\title{
LA PROTECCIÓN POR AFINIDAD DE LOS CIUDADANOS DE LA UNIÓN EUROPEA NO REPRESENTADOS EN TERCEROS PAÍSES \\ ELENA CRESPO NAVARRO' \\ ecrespo@umh.es
}

\author{
Cómo citar/Citation \\ Crespo Navarro, E.(2016). \\ La protección por afinidad de los ciudadanos de la Unión Europea \\ no representados en terceros países. \\ Revista de Derecho Comunitario Europeo, 55, 1019-1063. \\ doi: http://dx.doi.org/10.18042/cepc/rdce.55.07
}

\section{Resumen}

El 20 de abril de 2015 el Consejo de la Unión Europea aprobó, en aplicación de lo dispuesto en el art. 23 del Tratado de Funcionamiento de la Unión Europea, la Directiva (UE) 2015/637 sobre las medidas de coordinación y cooperación para facilitar la protección de los ciudadanos de la Unión no representados en terceros países por la que se deroga la Decisión 95/553/CE. El objeto de este trabajo es analizar el alcance, ámbito de aplicación y contenido de la protección por afinidad de los ciudadanos de la Unión no representados en terceros países regulado por la Directiva y la necesaria coordinación y cooperación entre los Estados miembros y con la Unión para hacerla efectiva en base al estudio de los antecedentes, de las normas actualmente vigentes y de la nueva regulación establecida en la citada Directiva.

\section{Palabras clave}

Ciudadanía de la Unión; protección y asistencia consular; protección por afinidad.

1 Profesora titular de Derecho Internacional Público y Relaciones Internacionales. Departamento de Ciencia Jurídica. Universidad Miguel Hernández. Titular de la Cátedra Jean Monnet. 


\title{
PROTECTION BY AFFINITY FOR UNREPRESENTED CITIZENS OF THE EUROPEAN UNION IN THIRD COUNTRIES
}

\begin{abstract}
On 20 April 2015, the Council of the European Union approved, pursuant to Article 23 of the Treaty on the Functioning of the European Union, the Directive (EU) 2015/637 on the coordination and cooperation measures to facilitate consular protection for unrepresented citizens of the Union in third countries and repealing Decision 95/553/EC. This research aims to analyze the effect and the scope of application of this protection due to a relation of affinity for unrepresented citizens in third countries. Moreover, particular focus will be given to the necessary coordination and cooperation among the member States and with the Union in order to make this right effective according to the study of the precedents, the current rules as well as the new regulation that is established in the above mentioned Directive.
\end{abstract}

\section{Keywords}

EU citizenship; consular protection; consular assistance; protection by affinity.

\section{LA PROTECTION PAR AFFINITÉ DES CITOYENS DE L'UNION EUROPÉENNE NON REPRÉSENTÉS DANS DES PAYS TIERS}

\section{Résumé}

Le 20 avril 2015 le Conseil de l'Union Européenne a approuvé la Directive (UE) 2015/637, en application de l'art. 23 du Traité de Fonctionnement de l'UE établissant les mesures de coordination et de coopération nécessaires pour faciliter la protection consulaire des citoyens de l'Union non représentés dans des pays tiers et abrogeant la Décision 95/553/CE. L'objectif de ce travail est l'analyse de l'atteinte, du champ d'application et du contenu de la protection par affinité des citoyens de l'Union non représentés dans des pays tiers et la nécessaire coordination et coopération entre les États membres et avec l'Union pour le faire effectif en se basant sur l'étude des antécédents des normes actuellement en vigueur et de la nouvelle régulation établie dans la nommée Directive.

\section{Mots clés}

Citoyenneté de l'Union, protection et assistance consulaire; Protection par affinité. 


\section{SUMARIO}

I. INTRODUCCIÓN. II. ANTECEDENTES: 1. Los orígenes de la protección; 2. La Decisión 95/553/CE; 3. La necesidad de revisión; 4. El Tratado de Lisboa. III. LA DIRECTIVA (UE) 2015/637 SOBRE LAS MEDIDAS DE COORDINACIÓN Y COOPERACIÓN PARA FACILITAR LA PROTECCIÓN DE LOS CIUDADANOS DE LA UNIÓN NO REPRESENTADOS EN TERCEROS PAÍSES: 1. Contexto y fundamento; 2. Estructura; 3. Objeto y ámbito de aplicación; 4. Contenido; 5 . Acceso a la protección y cooperación entre los Estados miembros; 6. Protección en casos de crisis; 7. Procedimientos financieros. IV. CONCLUSIONES.

\section{INTRODUCCIÓN}

Se calcula que alrededor de 90 millones de ciudadanos de la Unión Europea (UE) viajan cada año a terceros Estados y que cerca de 30 millones viven permanentemente fuera de la UE. Sin embargo, no todos los Estados miembros, ni mucho menos, disponen de una representación permanente y accesible en todos los terceros Estados. En realidad, solo en cuatro Estados terceros (China, Estados Unidos, India y Rusia) están representados todos los Estados miembros, mientras que hay determinadas zonas en las que la representación es especialmente escasa como Centroamérica, Caribe, Asia Central y África Central y Occidental. En tales circunstancias, actualmente puede haber unos siete millones de ciudadanos de la UE, que viajan o viven en un país en el que no existe una embajada o consulado de su nacionalidad, y esa cifra podría ampliarse hasta alcanzar los diez millones en $2020^{2}$.

No cabe duda de que se trata de un derecho que puede tener una gran relevancia práctica. Sin embargo, son todavía relativamente pocos los ciudadanos de la UE que recurren a este tipo de protección en terceros Estados, en buena medida por desconocimiento ${ }^{3}$. En el año 2015 se plantearon ante las

2 Reinforced consular protection for European citizens outside the EU, ficha técnica de la DG de Justicia y consumidores de la Comisión Europea, abril 2015.

3 Según el Eurobarómetro de 2006, solo un 23\% de los ciudadanos entrevistados conocía el derecho. Si bien las medidas dirigidas a mejorar la información de los ciudadanos 
representaciones de los Estados miembros en el extranjero 616 solicitudes de asistencia por ciudadanos de la UE no representados, la mayor parte en el Sur y Sudeste Asiático, y en el continente americano y, en su mayoría, referidas a pérdida o sustracción de documentación ${ }^{4}$.

El alcance y contenido del derecho ha sido objeto de diferentes interpretaciones, debido en gran parte a la confusión terminológica derivada de su propia regulación en los Tratados y en la normativa de desarrollo y a las diferentes posturas al respecto por parte de las instituciones, especialmente el Parlamento Europeo (PE) y la Comisión, y los Estados, y su ejercicio efectivo exige mejorar la coordinación y cooperación entre los agentes implicados, sobre todo los Estados miembros, principales responsables de garantizar la asistencia y protección de los nacionales en el extranjero, pero también con la propia UE, a través del Servicio Europeo de Acción Exterior (SEAE) y de sus delegaciones en terceros Estados.

El Tratado de Lisboa ${ }^{5}$ abrió nuevas posibilidades en este sentido, generando ciertas expectativas por las previsiones introducidas en varios aspectos.

adoptadas a propuesta de la Comisión (a las que nos referimos más adelante) parecen estar comenzando a dar sus frutos, pues según la información del Eurobarómetro de octubre de 2015, un $72 \%$ de los encuestados afirmaba ya conocerlo. Lo que previsiblemente tendrá sus consecuencias en un aumento de los casos en el futuro.

4 Los Estados cuyos nacionales solicitaron asistencia en más ocasiones fueron Suecia (65) e Italia (63), frente a solo 18 solicitudes de españoles (un $3 \%$ del total). Alemania fue quien mayor número de solicitudes recibió (107), seguida del Reino Unido (79), Bélgica (67), Dinamarca (60), Países Bajos (55) y Hungría (53). El resto de Estados miembros atendieron menos de 50 solicitudes cada uno. En cuanto a las regiones donde se produjeron las situaciones de necesidad, 226 casos se plantearon en el Sur y Sudeste Asiático, 117 en el continente americano, 79 en el norte de África y Oriente Medio, 76 en el este y sur de África, 71 en el oeste y centro de África y las demás distribuidas por el resto del planeta. Finalmente, respecto al tipo de protección requerida, 385 casos se referían a pérdida o sustracción de documentación, 57 a supuestos de arresto o detención, 20 casos de muerte, 11 de repatriación, 9 enfermedad grave o accidente, 5 víctimas de violencia y 129 a otros tipos de protección. Véase Doc. 8347/16 (adenda 2), de 29 de abril de 2016. Datos recopilados por el Servicio Europeo de Acción Exterior (SEAE) y expuestos en abril de 2016 ante el Grupo de Asuntos Consulares del Consejo. La primera vez que se llevó a cabo una recopilación sistemática de esta clase de datos fue en el año 2015 (Información obtenida de manera oficiosa de la Dirección General de Españoles en el Exterior y de Asuntos Consulares y Migratorios).

5 Tratado de Lisboa por el que se modifica el Tratado de la Unión Europea y el Tratado Constitutivo de la Comunidad Europea, de 13 de diciembre de 2007, versión consolidada, DO C 202, de 7 de junio de 2016. 
En concreto, la posibilidad de desarrollo mediante directivas, recogida en el art. 23 del Tratado de Funcionamiento de la Unión Europea (TFUE), ha permitido que el 20 de abril de 2015 se aprobase la Directiva 2015/637 del Consejo sobre las medidas de coordinación y cooperación para facilitar la protección consular de ciudadanos de la UE no representados en terceros países y por la que se deroga la Decisión 95/553/CE .

El objeto de este estudio es el análisis del contenido, naturaleza y alcance del derecho a la luz de la citada Directiva, así como las medidas de coordinación y cooperación previstas en dicha norma para garantizar su aplicación efectiva por parte de los Estados miembros con el apoyo de la UE. No obstante, consideramos conveniente hacer un breve recordatorio de los antecedentes, a los que dedicamos el primer apartado del trabajo, para valorar la evolución que la Directiva puede suponer al respecto.

\section{ANTECEDENTES}

\section{LOS ORIGENES DE LA PROTECCIÓN}

La posibilidad de acogerse a la protección de las autoridades diplomáticas y consulares de cualquier Estado miembro se introduce en el texto de los Tratados constitutivos en el marco del estatuto de ciudadanía de la UE que se crea, al mismo tiempo que la propia UE, con la reforma de Maastricht ${ }^{7}$. Ahora

\footnotetext{
DO L 106, de 24 de abril de 2015.
}

7 Tratado de la Unión Europea, adoptado en Maastricht el 7 de febrero de 1992, BOE de 13 de enero de 1994. Art. 8.C TCE: «Todo ciudadano de la Unión podrá acogerse, en el territorio de un tercer país en el que no esté representado el Estado miembro del que sea nacional, a la protección de las autoridades diplomáticas y consulares de cualquier Estado miembro, en las mismas condiciones que los nacionales de dicho Estado. Antes del 31 de diciembre de 1993, los Estados miembros establecerán entre sí las normas necesarias y entablarán las negociaciones internacionales requeridas para garantizar dicha protección». Por su parte, el art. J.6 TUE disponía: «Las misiones diplomática y consulares de los Estados miembros y las delegaciones de la Comisión en los terceros países y en las Conferencias internacionales, así como sus representaciones ante las organizaciones internacionales, cooperarán para garantizar el respeto y la ejecución de las posiciones comunes adoptadas por el Consejo. Intensificarán su cooperación intercambiando información, procediendo a valoraciones comunes y contribuyendo a la ejecución de las disposiciones contempladas en el art. 8C del Tratado constitutivo de la Comunidad Europea». El art. 8C pasó con el Tratado de Ámsterdam, de 2 de octubre de 1997 (versión consolidada en DO C 340, de 10 de 
bien, no se trataba de una novedad absoluta. El Tratado de Maastricht confirmaba una práctica de protección, a la que puede calificarse de protección por afinidad, que se había ido gestando desde los años ochenta por los Estados miembros de las entonces Comunidades Europeas al calor de la cooperación diplomática y consular que desarrollaban a nivel intergubernamental ${ }^{8}$.

Hablamos de protección por afinidad ${ }^{9}$ para referirnos a un tipo de protección que ejercen en la práctica los sujetos de derecho internacional respecto de las personas, con independencia de su nacionalidad, movidos en parte por consideraciones humanitarias, pero también por la existencia de algún tipo de vinculación especial, distinta de la nacionalidad. Ese nexo no siempre es el mismo, sino que varía de unos casos a otros, pero en todos ellos sirve de base para otorgar al particular una protección muy similar a la protección y asistencia consular tradicionalmente reservadas a los nacionales.

Por recordar algún precedente, ya en las Directrices establecidas por el Comité Político de la Cooperación Política Europea (CPE) el 17 de mayo de 1984 sobre la actuación a seguir en situaciones catastróficas o crisis políticas, visitas a detenidos, secuestro de menores y otras cuestiones ${ }^{10}$ se decidía crear

noviembre de 1997), a ser art. 20 TCE con contenido idéntico, que se mantuvo con el Tratado de Niza de 26 de febrero de 2001, (versión consolidada en DO C 325, de 24 de diciembre de 2002). Actualmente, es el art. 23 TFUE. El art. J.6 se convirtió primero en art. 20 TUE y, actualmente, en el art. 35 TUE.

8 Según C. Jiménez Piernas: «El derecho de asistencia del artículo $8 \mathrm{C}$ no se configura ex novo sino en virtud de una determinada práctica de los Estados miembros de las Comunidades Europeas anterior incluso a la que se ha venido gestando en el ámbito de la Cooperación Política Europea [...] solo ha pretendido en rigor constitucionalizar formalmente y fortalecer políticamente dicha práctica», Carlos JIMÉNEZ PIERNAS, "La protección diplomática y consular del ciudadano de la Unión Europea», RIE, vol. 20, núm. 1, 1993, pp. 9-49, p. 35; y «La asistencia consular al ciudadano de la Unión: de Maastricht a Ámsterdam, en Fernando MARIÑO MENÉNDEZ (ed.), Acción exterior de la Unión Europea y de la comunidad internacional, Madrid, 1998, pp. 219-242, p. 229.

9 Sobre el concepto, tipología y precedentes de lo que denominamos protección por afinidad, Elena CRESPO NAVARRO, Nuevas formas de protección del individuo en Derecho Internacional. La erosión del vínculo de la nacionalidad, Valencia, 2005, pp. 277-376.

10 Directrices recogidas por España en la Orden Circular del Ministerio de AA. EE. núm. 3078, de 5 de mayo de 1986, que establecía: «Las secciones consulares de las Embajadas de España y los consulados deberán proteger a nuestros nacionales y a aquellos ciudadanos de países comunitarios que carezcan de representación consular o diplomática en el lugar, o que no puedan comunicarse con las mismas, y documentarles, si fuera necesario, con un salvoconducto que les permita viajar para su 
un grupo de trabajo de cooperación consular que se reuniría al menos trimestralmente y prepararía las actuaciones a seguir en caso de catástrofe o crisis política $^{11}$. Poco después, los Ministros de Asuntos Exteriores (AA. EE.) de los Estados miembros en el seno de la CPE adoptaron una Decisión con ocasión de la firma del Acta Única Europea acordando intensificar la cooperación, llevar a cabo reuniones regulares de los jefes de misión de los Estados miembros y el representante de la Comisión en terceros países, elaborar informes comunes cuando la situación lo exigiera, y valorar la posibilidad de prestar asistencia en terceros países a los nacionales de los Estados miembros no representados ${ }^{12}$.

De hecho, la preparación de las normas de desarrollo del art. 8C TCE comenzó antes incluso de la entrada en vigor del Tratado de Maastricht ${ }^{13}$, mediante la adopción por el Comité Político de la CPE en 1993 de unas directrices conforme a las cuales los nacionales en situación de dificultad de un Estado miembro que no estuviera representado en un tercer país podrían recurrir a las representaciones diplomáticas de otros Estados miembros en busca de ayuda y posible repatriación, especialmente en casos de muerte, accidente, ataque con violencia, enfermedad grave o arresto ${ }^{14}$. En 2006, el Grupo

regreso a su país de origen [...]». Respecto a visitas a ciudadanos detenidos señalaba: «En las visitas que efectúe V. a españoles detenidos deberá poner especial cuidado en comprobar si existen otros detenidos ciudadanos de países comunitarios y — si fuera posible- establecer contactos con ellos y averiguar sus necesidades, informando de cuanto averigüe a la misión diplomática o consular que corresponda y en caso de dificultad a este Departamento, que trasladará la información al Ministerio de AA. EE. correspondiente». MINISTERIO DE ASUNTOS EXTERIORES, Recopilación de órdenes circulares vigentes, Madrid, 1999, pp. 158 y ss.

11 Entre ellas, un programa de evacuación que incluiría medidas como preparar un inventario de los recursos y medios de transporte a utilizar en caso de crisis; disponer de las señas y modo de contactar con los ciudadanos de los Estados miembros residentes; prever puntos de encuentro y medios de comunicación y rutas de evacuación, o coordinar las gestiones a realizar ante las autoridades locales. Se destacaba asimismo la conveniencia de intercambiar información sobre asuntos como la situación de extranjeros detenidos, la legislación aplicable y la experiencia en las relaciones con las autoridades locales en esos ámbitos y, en caso necesario, de realizar acciones conjuntas para mejorar la situación de los ciudadanos comunitarios detenidos en el extranjero, poniendo especial interés en las repatriaciones. Disposición II de la Decisión, Boletín CE, 2-1986, pp. 121-122.

13 Como señaló la propia Comisión Europea en su primer informe sobre la ciudadanía de la UE, COM (1993) 702 final, 21 de diciembre, p. 7.

14 Directrices para la protección de los ciudadanos comunitarios que no contaran con representación por las representaciones diplomáticas comunitarias en terceros paises, aprobadas por el Comité Político en su reunión de 29 y 30 de marzo de 1993, de las que se 
de Trabajo sobre Asuntos Consulares del Consejo (COCON) elaboró nuevas Directrices que fueron aprobadas por el Consejo y actualizadas en $2010^{15}$.

\section{LA DECISIÓN 95/553/CE}

Habría que esperar hasta 1995, casi dos años después de la entrada en vigor del TUE, para que se adoptara, como desarrollo del antiguo art. 8C TCE, la Decisión 95/553/CE de los representantes de los Gobiernos de los Estados miembros reunidos en el seno del Consejo, de 19 de diciembre de 1995, relativa a la protección de los ciudadanos de la UE por las representaciones diplomáticas y consulares ${ }^{16}$.

Esta Decisión, muy similar en su contenido a las Directrices de 1993, establece un sistema común de protección de los ciudadanos de la UE en terceros países que se concreta, en su art. 5.1, en la asistencia en casos de fallecimiento, accidente o enfermedad graves, arresto o detención, víctimas de actos de violencia, y socorro y repatriación en casos de dificultad. No es, sin embargo, una lista cerrada, pues el art. 5.2 añade que las autoridades diplomáticas y consulares podrán asistir también en otros casos a los ciudadanos de la UE que lo soliciten, siempre dentro de sus competencias.

La regulación se vio completada por la Decisión 96/409/PESC de los representantes de los Gobiernos de los Estados miembros reunidos en el seno

informó mediante nota verbal de la Presidencia a las delegaciones de la Comisión y a las autoridades de todos los Estados miembros, que a su vez, las hicieron públicas a través de comunicados de prensa de sus respectivos Ministerios de AA. EE. En España dicha información se hizo pública el 15 de junio de 1993, Cronología OID (1993), p. 11.

15 Directrices de 2006, en Doc. 10109/06, de 2 de junio de 2006; y Directrices actualizadas, en Doc. 15613/10, de 5 de noviembre de 2010.

16 DO L 314, de 20 de diciembre de 1995, pp. 73-76, para cuya aplicación práctica se adoptó la Decisión de los representantes de los Gobiernos de los Estados miembros sobre las medidas de aplicación de la Decisión 95/553/CE, Doc. 11107/95, de 19 de diciembre de 1995; y, posteriormente, unas Directrices no vinculantes para la aplicación complementaria de una serie de disposiciones de la Decisión 95/553/CE, Doc. 11113/08, de 24 de junio de 2008. En España, el texto de la Decisión 95/553/CE se recogió en el capítulo I de la Orden Circular núm. 3213 del Ministerio de AA. EE. español, de 29 de febrero de 1996, «Directrices sobre protección a nacionales de países de la UE en terceros países por Embajadas y Oficinas consulares de los demás países de la Unión", que en su capítulo II se refiere a los supuestos, forma en que debe prestarse la asistencia y procedimiento a seguir por la misión diplomática u oficina consular en cada caso, MINISTERIO DE AA. EE., op. cit., pp. 437-455. 
del Consejo, de 25 de junio de 1996, relativa al establecimiento de un documento provisional de viaje; documento que tiene por objeto facilitar a los ciudadanos de la UE no representados que se encuentran en dificultades en el extranjero, el regreso al país de su nacionalidad, de su residencia permanente o, excepcionalmente, a otro destino ${ }^{17}$.

La protección se prevé en la Decisión 95/553/CE con carácter subsidiario, es decir, el ciudadano de la UE solo podrá beneficiarse de la misma si en el territorio en el que se encuentra no existe ni representación permanente accesible, ni cónsul honorario accesible y competente (art. 1) ${ }^{18}$. Las representaciones diplomáticas y consulares podrán convenir entre sí acuerdos prácticos que permitan la gestión eficaz de las solicitudes de protección $(\text { art. 4) })^{19}$ y las que concedan la protección deberán otorgar a los solicitantes nacionales de otros Estados miembros el mismo trato que a sus propios nacionales $\left(\right.$ art. 3) ${ }^{20}$. Finalmente, la Decisión establece que, sin perjuicio de la

17 DO L 168, de 6 de julio de 1996, pp. 4-11. El documento provisional de viaje puede ser expedido por cualquier Estado miembro en casos de pérdida, robo o destrucción o cuando no esté disponible temporalmente el pasaporte o documento original de viaje, previa autorización del Estado de nacionalidad (un formato uniforme figura en el anexo I de la Decisión). La Comisión destacó en 2011 el interés de algunos Estados miembros por reforzar los elementos de seguridad incorporados en tales documentos y los problemas que plantea para algunos terceros Estados su aceptación en su versión actual sin elementos biométricos y se comprometió a estudiar una adaptación del formato llevando a cabo un análisis detallado de la relación coste-beneficio, Comunicación de la Comisión al Consejo, al PE, al Comité Económico y Social y al Comité de las Regiones, Protección consular para los ciudadanos de la UE en terceros paises: Situación actual y perspectiva futura, COM (2011) 149 final, de 23 de marzo, p. 13.

18 El carácter subsidiario de la protección ha sido destacado por la doctrina. Antes incluso de la adopción de la Decisión, Carlos JIMÉNEZ PIERNAS, «La protección diplomática y consular..., loc. cit. pp. 19 y 41; «La asistencia consular al ciudadano...», loc. cit., pp. 240-241. También Paz ANDRÉS SÁENZ DE SANTAMARÍA, "La protección diplomática y consular de los ciudadanos de la Unión en el exterior», Revista de Derecho de la Unión Europea, núm. 11, 2006, pp. 11-25, pp. 12-13.

19 En las citadas Directrices para la aplicación complementaria de una serie de disposiciones de la Decisión 95/553/CE se explica que tales acuerdos prácticos deberían incluir la asistencia por un Estado miembro distinto al de nacionalidad cuando así lo aconseje la falta de recursos o de conocimientos expertos de la representación del Estado de nacionalidad.

20 E. Vilariño señaló que la referencia del art. 8C a la posibilidad de acogerse a la protección «en las mismas condiciones que los nacionales» debía entenderse referida a los requisitos y forma de ejercicio de las funciones que el ciudadano puede solicitar, mientras que respecto del fondo de la protección sería de aplicación el derecho del 
obligación de tratar a los solicitantes como a los propios nacionales y, salvo casos de extrema urgencia, no podrá comprometerse ni concederse al ciudadano de la UE anticipo, ayuda económica o gasto sin la previa autorización de las autoridades competentes del Estado de nacionalidad y, a menos que dichas autoridades renuncien a ello, el solicitante ha de comprometerse al reembolso de todo el anticipo, ayuda o gasto, incluida la tasa consular notificada $^{21}$.

El sistema de protección previsto en el Tratado y desarrollado por la Decisión 95/553/CE se caracteriza, como también se ha destacado en numerosas ocasiones, por estar condicionado a la aceptación o, al menos, no oposición de los terceros Estados, ya que se ejerce al margen del vínculo de la nacionalidad. Por ello hace referencia el Tratado a las negociaciones internacionales requeridas para su puesta en práctica.

Existe también acuerdo en la doctrina sobre el alcance limitado del derecho $^{22}$, pues a pesar de la terminología utilizada, su contenido no es asimilable

Estado de nacionalidad, Eduardo VILARIÑO PINTOS, «Representación exterior y cooperación diplomática y consular en el Tratado de la Unión Europea», RIE, vol. 22 núm. 2, 1995, pp. 417-443, p. 440. Para C. Jiménez Piernas dicha fórmula implicaba que la protección debía hacerse «de acuerdo con los preceptos constitucionales y legislativos, así como con la práctica diplomática y consular de cada Estado miembro", JIMÉNEZ PIERNAS, «La protección diplomática y consular..., loc. cit. p. 20. Sobre el carácter no discriminatorio de la protección, véase Carlos JIMÉNEZ PIERNAS, «Estatuto de ciudadanía y derecho de asistencia a los ciudadanos de la Unión Europea», en Fernando MARIÑO MENÉNDEZ (dir.), Derecho internacional y Tratado constitucional europeo, Madrid, 2006, pp. 449-461.

21 El compromiso de reembolso ha de constar en un documento (se incluyen modelos en los anexos I y II de la Decisión) por el que se exija a la persona en dificultades el reembolso al Gobierno de su Estado que, a su vez, reembolsará todos los gastos a petición del Estado miembro que prestó la asistencia (art. 6).

22 Entre otros, ANDRÉS SÁENZ DE SANTAMARÍA, loc. cit., pp. 17-15; Cesáreo GUTIÉRREZ ESPADA, «El Servicio Europeo de Acción Exterior: ¿̇solo una hermosa fachada para la inanidad?», Cuadernos Europeos de Deusto, núm. 44, 2011, pp. 63-92, p. 86; JIMÉNEZ PIERNAS, «La protección diplomática y consular..., loc. cit. pp. 31-49, y "Estatuto de ciudadanía y derecho de asistencia...", loc. cit., pp. 459-460; Araceli MANGAS MARTÍN, "Artículo 46. Protección diplomática y consular», en Araceli MANGAS MARTÍN (Dir.), Carta de los derechos fundamentales de la Unión Europea. Comentario artículo por artículo, 731-736, p. 735; Adela REY ANEIROS, "Hacia el reforzamiento de la dimensión exterior de la ciudadanía europea», Revista de Derecho Comuntario Europeo, núm. 26, 2007, pp. 9-43, pp. 24-28, y Juan M. RODRÍGUEZ BARRIGÓN, La ciudadanía de la Unión Europea, Madrid, 2002, pp. 559-569. 
al de la protección diplomática en sentido estricto ${ }^{23}$, ni al de la protección y asistencia consular. En efecto, de acuerdo con el art. 1 del Proyecto de la CDI sobre Protección Diplomática ${ }^{24}$, este tipo de protección de nacionales consiste en «la invocación por un Estado, mediante la acción diplomática o por otros medios de solución pacífica, de la responsabilidad de otro Estado por el perjuicio causado por un hecho internacionalmente ilícito de ese Estado a una persona natural o jurídica que es un nacional del primer Estado con miras a hacer efectiva esa responsabilidad».

De manera que resulta esencial para que pueda hablarse de protección diplomática en sentido estricto y no de otras formas de protección, que se invoque la responsabilidad del Estado autor del hecho internacionalmente ilícito mediante una reclamación formal. Por su parte, la protección consular ${ }^{25}$,

23 El término "protección diplomática» se emplea en diversos sentidos y esa pluralidad de significados exige adoptar «una especial cautela al estudiar la práctica diplomática en la materia. Actuaciones de los Estados realizadas en el sentido más general y amplio de la protección diplomática no pueden interpretarse como precedentes en favor de las normas internacionales que contemplan la protección diplomática en un sentido formal o estricto", Manuel DÍEZ DE VELASCO, "Reflexiones sobre la protección diplomática», en VV. AA., Pensamiento jurídico y Sociedad internacional. Estudios en honor del Prof. D. Antonio Truyol Serra, 2 vols., Madrid, 1986, vol. I, pp. 377-391, pp. 384-385.

24 Puede consultarse el art. 1 junto con sus comentarios en capítulo IV del Informe de la CDI sobre la labor realizada en su $58^{\circ}$ periodo de sesiones (2006), Asamblea General. Documentos oficiales. $61^{\circ}$ periodo de sesiones. Suplemento núm. 10 (A/61/10), Naciones Unidas. Nueva York, pp. 15-113, pp. 27-32.

25 De forma general se define la protección consular como la acción que un funcionario consular ejerce ante las autoridades locales del Estado receptor para prestar ayuda y asistencia a los nacionales del Estado acreditante que residen o se encuentran en su circunscripción consular, Santiago MUÑOZ MACHADO, Diccionario del español jurídico, Madrid, 2016, p. 1365. E. Vilariño recuerda que la protección consular en sentido estricto es una función originaria de la institución consular, de carácter general, con base en el derecho consuetudinario, a cuyo ejercicio no puede oponerse el Estado receptor, que consiste en el derecho de reclamación formal ante la autoridad local correspondiente, solicitando la reparación que se estime pertinente, en defensa de los derechos e intereses legítimos de los nacionales personas físicas o jurídicas, es decir, el standard mínimum, cuando estos han sido lesionados por una autoridad local competente en la circunscripción de la oficina consular. Su ejercicio requiere que el lesionado sea nacional del Estado de envío, que la lesión sea consecuencia de la violación de una norma de derecho interno del Estado receptor, si bien indirectamente implicará una violación del derecho internacional y que se haya agotado la vía interna posible ante las autoridades locales competentes. Como señala el autor, la protección 
que no se lleva a cabo en el plano internacional sino en el ámbito interno del Estado territorial, es la acción que el cónsul ejerce ante las autoridades locales del Estado receptor en favor de los nacionales del Estado acreditante que residen o se encuentran ocasionalmente en su distrito consular y han recibido un trato distinto al debido como consecuencia de una acción de las autoridades locales que infrinja las normas de derecho internacional o del ordenamiento interno, que regulan el trato a los extranjeros en general o a los nacionales de dicho Estado en particular. Finalmente, la asistencia consular ${ }^{26}$, que no presupone la existencia de un comportamiento antijurídico ni conlleva la presentación de reclamación, pero también está condicionada por la nacionalidad, se concreta en una serie de funciones ejercidas por el cónsul, con el fin de proteger los intereses de sus connacionales que se encuentran en dificultades en el Estado territorial, prestándoles ayuda y asistencia. Por ejemplo, mediante auxilio material en casos de fallecimiento, enfermedad o accidente, o de asistencia a los nacionales detenidos o presos ${ }^{27}$.

La entrada en vigor de la Decisión 95/553/CE no se produciría hasta mayo de $2002^{28}$, pero esa demora no impidió que, en la práctica, todos los Estados miembros adoptasen las medidas necesarias para que sus representaciones diplomáticas y consulares pudieran ofrecer a los ciudadanos de la UE

consular, a diferencia de la protección diplomática, no es discrecional sino obligatoria, por lo que el Estado, a través de su oficina consular, no puede excusarse de su ejercicio cuando se le solicita, Eduardo VILARIÑO PINTOS, Curso de Derecho Diplomático y Consular, $5^{\mathrm{a}}$ ed., Madrid, 2016, p. 385.

26 Se habla asimismo de "asistencia diplomática», definida como la ayuda que se dispensa a favor de un nacional, ordinariamente en o desde una misión diplomática, sin necesidad de que haya tenido que mediar un hecho ilícito por parte del Estado receptor, MUÑOZ MACHADO, op. cit., p. 204.

27 Sobre el concepto de protección diplomática y la distinción de figuras afines, Carlos JIMÉNEZ PIERNAS (dir.), Introducción al Derecho internacional Público. Práctica de España y de la Unión Europea, Madrid, 2011, pp. 425-426; Adolfo MARESCA, Las relaciones consulares, Madrid, 1974, pp. 215-231; y José Antonio PASTOR RIDRUEJO, Curso de Derecho Internacional Público y Organizaciones internacionales, 20a ed., Madrid, 2016, pp. 269-271, 521, y 552-553. Sobre el ordenamiento español, Raúl I. RODRÍGUEZ MAGADALENO y Beatriz VÁZQUEZ RODRÍGUEZ, «Protección de la ciudadanía española en el exterior», en M. Ludivina VALVIDARES SUÁREZ, (coord.), Derechos y garantías frente a las situaciones de vulnerabilidad, Oviedo, 2016, 381-400, pp. 394-399.

28 Cuarto informe de la Comisión sobre ciudadanía, COM (2004) 695 final, de 26 de octubre. 
no representados en un tercer Estado la asistencia necesaria en los casos a los que dicha norma se refiere ${ }^{29}$.

\section{LA NECESIDAD DE REVISIÓN}

Las graves situaciones de crisis y emergencias de diferente naturaleza en las que la UE y sus Estados miembros tuvieron que actuar y en las que se vieron envueltos numerosos ciudadanos de la UE pusieron de manifiesto la necesidad de mejorar la coordinación al respecto entre los Estados miembros y con la UE. Por ello, el Consejo Europeo, en su reunión de Bruselas de 15 y 16 de junio de $2006^{30}$, aprobó el informe de la Presidencia austriaca que hacía referencia a la protección de los ciudadanos en el exterior y planteó la necesidad de seguir avanzando para reforzar la cooperación entre los Estados miembros, e incluso la creación de puntos de asistencia consular recíproca en regiones determinadas de antemano ${ }^{31}$.

Con el objetivo de mejorar la aplicación efectiva del derecho, la Comisión presentó en 2006 un libro verde sobre la protección diplomática y consular de los ciudadanos de la UE en terceros países ${ }^{32}$, en el que buscaba incitar a la reflexión sobre ciertas cuestiones. En concreto, la necesidad de ampliar la información al ciudadano; de determinar el alcance de la protección y de negociar con terceros países para lograr su consentimiento, y de fijar las estructuras y recursos con que la UE debería contar en este ámbito. Como resultado de la consulta pública abierta con el libro verde, la Comisión presentó

29 Tercer informe de la Comisión sobre ciudadanía, COM (2001) 506 final, de 7 de septiembre. Aunque en la Decisión 95/553/CE se había previsto su revisión a los 5 años de su entrada en vigor a la vista de la experiencia adquirida (art. 7), no se produjo esa revisión.

30 Conclusiones del Consejo Europeo de Bruselas, 15 y 16 de junio de 2006, Doc. 10633/06, de 16 de junio de 2006, puntos 12-14.

31 ANDRÉS SÁENZ DE SANTAMARÍA, loc. cit., pp. 16-17. Dicho informe, titulado Fortalecimiento de las capacidades de respuesta a emergencias y crisis, (Doc. 10551/06, de 15 de junio de 2006) se basaba a su vez en el informe presentado el 9 de mayo de 2006 por Michel Barnier al presidente del Consejo y al presidente de la Comisión, Para una fuerza europea de protección civil. Europe Aid, en el que proponía una serie de medidas para instaurar un sistema de protección civil dentro y fuera de la UE que incluía la protección diplomática y consular.

32 COM (2006) 712 final, de 28 de noviembre. Anteriormente, la Comisión ya había presentado algunas propuestas en su Comunicación sobre la aplicación del Programa de La Haya: el camino a seguir, COM (2006) 331 final, de 28 de junio. 
el Plan de Acción para el Periodo 2007-200933, en el que recogía ya una serie de medidas concretas sobre los cuatro ámbitos señalados para la reflexión.

A la vista de las respuestas obtenidas sobre el libro verde, la Comisión consideró imprescindible, en primer lugar, mejorar la información ${ }^{34}$, pues constataba que una de las razones de la escasa aplicación práctica de la protección era el desconocimiento de los ciudadanos ${ }^{35}$.

33 Comunicación de la Comisión al Consejo, al PE y al Comité de las Regiones, Protección consular eficaz en los terceros paises: la contribución de la Unión. Plan de Acción 2007-2009, COM (2007) 767 final, de 5 de diciembre.

34 Sobre el libro verde, puede verse REY ANEIROS, loc. cit., p. 29. Entre las ideas que la Comisión lanzó para mejorar la información al ciudadano, estaban las de difundir folletos en aeropuertos, puertos, estaciones y entre los profesionales implicados (como agencias de viajes); ofrecer información a través de Internet (en el sitio Europa y en las páginas de las delegaciones de la Comisión en terceros Estados); invitar a los Estados miembros a reproducir el art. 20 TCE en los pasaportes; publicar y actualizar los datos de las embajadas y oficinas consulares de los Estados miembros representados en terceros Estados; presentar de forma coordinada las recomendaciones de viaje de los diferentes Estados miembros; y dar a conocer, por ejemplo, a través del $D O$, cualquier medida vinculada a la aplicación del art 20 TCE. Tales medidas fueron respaldadas por el Comité Económico y Social en su Dictamen sobre el libro verde de la Comisión, de 4 de marzo de 2007 (DO C 161, de 13 de julio de 2007, pp. 75-79), que proponía además implicar a organizaciones empresariales y de empleadores y a las ONG en la difusión de información (pues muchas personas no viajan por motivos turísticos sino como empresarios, comerciantes, empleados, o voluntarios de ONGs); y la reproducción obligatoria del art. 20 TCE, en los pasaportes. También el PE, en su Resolución sobre el libro verde La protección diplomática y consular del ciudadano de la Unión en los terceros países, de 11 de diciembre 2007, Doc. 2007/2196 (INI), respaldó las propuestas de la Comisión a la que pidió intensificar ese esfuerzo de información, proponiendo además habilitar un número de teléfono europeo único de emergencia, elaborar una recomendación de buenas prácticas sobre los consejos a los viajeros y centralizarlos en una página web (punto 6). En ese sentido, la Comisión lanzó en abril de 2007 una campaña de información con carteles y folletos que fue acompañada de la difusión de la información a nivel nacional por los propios Estados miembros. Campaña que continuó en 2008, ver COM (2007), 767 final, p. 6 y COM (2011) 149, final, p. 7.

35 Para lograrlo, decidió adoptar el 5 de diciembre de 2007 la Recomendación sobre la reproducción del tenor del art. 20 TCE en los pasaportes, C (2007) 5841, DO L 118, de 6 de mayo de 2008, pp. 30-31. En 2011, la mayoría de Estados la habían incluido (solo ocho Estados habían decidido no hacerlo o no habían decidido nada al respecto), COM (2011) 149 final, ya citado, p. 7. Además, la Comisión decidió que se creara un sitio Web específico para comunicar las medidas de aplicación del art. 20 
En segundo lugar, sobre el alcance y contenido de la protección ${ }^{36}$, la Comisión reconoció que, a pesar de las diferentes interpretaciones existentes, los casos en los que los ciudadanos solicitan ayuda en la práctica se limitan a la protección consular ${ }^{37}$. Por ello, y a pesar de la petición expresa del PE de incluir la protección diplomática en el ámbito de la protección, decidió que las medidas propuestas en adelante se limitarían a la protección consular, pero sin descartar una posible acción futura en el ámbito de la protección diplomática. Y, en lo referido a la extensión de los beneficiarios, la Comisión propuso incluir a los miembros de la familia del ciudadano de la UE nacionales de terceros Estados, tras destacar que la ausencia de protección en tales casos

TCE e informar de las representaciones de los Estados miembros en el exterior (con enlace a las recomendaciones de viaje que publican los Estados miembros), así como examinar la posibilidad de ofrecer información vía telefónica.

36 La Comisión había propuesto en el libro verde estudiar a largo plazo las divergencias entre las normas y prácticas nacionales; añadir, entre los tipos de protección, los aspectos relacionados con la definición y repatriación de restos mortales; simplificar los procedimientos de concesión de anticipos, y extender el ámbito de aplicación personal de la protección. Propuestas que fueron apoyadas por el Comité Económico y Social que, respecto al reembolso de los gastos, recomendó incluso prever que se efectuara directamente a la entidad que facilita la ayuda, la renuncia al mismo en caso de cantidades mínimas y un sistema de compensación de gastos entre los Estados miembros. Además, propuso atribuir valor jurídico vinculante a las Directrices sobre protección consular aprobadas por el Consejo. El PE en su Resolución sobre el libro verde va más allá al considerar imprescindible «crear sin demora las condiciones para revisar la Decisión de 1995 con el fin de ampliarla y de incluir sin ambigüedad la protección diplomática dentro del ámbito de la misma» (considerando K) y pedir a la Comisión que tras la entrada en vigor del Tratado de Lisboa presentase una propuesta de modificación de la decisión de 1995 que incluyese expresamente la protección diplomática, la identificación y repatriación de restos mortales y la simplificación de los procedimientos de concesión de anticipos y ayudas económicas (punto 8).

37 Si bien la definición amplia que ofrece la Comisión, poco rigurosa desde una perspectiva jurídica, parece referirse más a la asistencia consular o la asistencia diplomática, pues dice: «La protección consular es la ayuda y la asistencia que presta un Estado a ciudadanos en el extranjero, ya sean sus propios nacionales, ya sean nacionales a los que ha acordado prestar asistencia. Puede ser prestada por las autoridades diplomáticas o consulares», COM (2007) 767 final, p. 8. La doctrina ha destacado esa falta de rigor jurídico, que se aprecia, especialmente en los documentos de trabajo y denota la dificultad de llegar a un acuerdo entre los Estados miembros y las Instituciones sobre el alcance y contenido del derecho, Mónica GUZMÁN ZAPATER, «La protección consular como derecho derivado de la ciudadanía», RDCE, núm. 27 (2014), 259279, p. 260; en el mismo sentido REY ANEIROS, loc. cit., pp. 24-28. 
podía suponer importantes dificultades y molestias en la práctica ${ }^{38}$, pero dejó al margen, en cambio, a los refugiados, a los apátridas y a otros no nacionales residentes en un Estado miembros a pesar de la solicitud del $\mathrm{PE}^{39}$. Propuso, asimismo, considerar la simplificación de los procedimientos de repatriación de restos mortales y de concesión de anticipos económicos y crear un sistema de compensación entre Estados miembros.

En tercer lugar, para garantizar la aceptación de la protección por los terceros Estados, la Comisión entiende que, aunque la previa notificación y ausencia de oposición del tercer Estado sería suficiente ${ }^{40}$, la obtención del consentimiento expreso mejoraría la seguridad jurídica y daría un significado a la ciudadanía europea en el exterior. Por ello, recomienda a los Estados miembros negociar una cláusula estándar de consentimiento en sus acuerdos bilaterales con terceros Estados, y propone también la inclusión de una cláusula de ese tipo en los futuros acuerdos mixtos, e incluso a largo plazo, considerar la posibilidad de obtener el consentimiento para que la propia UE pudiera ejercer la protección a través de las delegaciones de la Comisión en casos relacionados con competencias comunitarias, sin perjuicio de la responsabilidad principal que a estos efectos recae sobre los Estados ${ }^{41}$.

38 Sobre todo a la vista de que más de 6 millones de ciudadanos de la UE estaban por entonces casados con nacionales de terceros Estados y de que algunos Estados miembros ya recogían esa posibilidad.

39 En su Resolución sobre el libro verde, el PE propuso extender la protección no solo a los miembros de la familia nacionales de terceros Estados, sino también a los refugiados, apátridas y «a otras personas que no sean nacionales de ningún país pero residan en un Estado miembro y sean titulares de un documento de viaje expedido por dicho Estado miembro» (punto 9).

40 Según el art. 8 del Convenio de Viena sobre relaciones consulares de 24 de abril de 1963: «Una oficina consular del Estado que envía podrá, previa la adecuada notificación al Estado receptor y siempre que este no se oponga, ejercer funciones consulares por cuenta de un tercer Estado en el Estado receptor», BOE, de 6 de marzo de 1970.

41 La Comisión se refería específicamente a la protección o asistencia dispensada a través de las delegaciones de la Comisión en terceros países en favor de los pescadores comunitarios en caso de apresamiento o embargo de buques pesqueros con pabellón de un Estado miembro y detención del capitán y la tripulación y a las competencias de la Comisión previstas al respecto en algunos acuerdos de pesca. Esa propuesta se planteaba al calor de la Sentencia de 6 de julio 1995 del Tribunal de Primera Instancia, en el Asunto Odigitria c. Consejo y Comisión, T-572/93, Rec.1995-7/8, p. II-2025. Sobre este tema, Jesús CARRERA HERNÁNDEZ, Politica pesquera y responsabilidad de la Comunidad Europea, Salamanca, 1995, pp. 252-261; del mismo autor «El deber de asistencia diplomática y consular de los pescadores comunitarios por la Comunidad 
Por último, sobre la necesidad de fijar estructuras y recursos, la Comisión insistió en la necesidad de mejorar la formación de los funcionarios de los Estados miembros y de las instituciones, y el intercambio de buenas prácticas. Recordó la existencia de acuerdos de coubicación entre las representaciones de algunos Estados miembros en terceros países ${ }^{42}$ y propuso la creación de

Europea (Comentario a la Sentencia del TPI de 6 de julio de 1995, Odigitria AAE c. Consejo y Comisión, as. T-572/93, RIE, vol. 23, núm. 2 (1996), pp. 539-552; y «Protección diplomática y responsabilidad extracontractual de la Comunidad Europea en el ámbito pesquero", Noticias UE, núm. 161. (1998), pp. 27-33; Theodoros KATSOUFROS, «Réflexions sur l'arrêt Odigitria du TPI des Communautés Européennes, $A F D I$, 1995, pp. 711-727, y RODRÍGUEZ BARRIGÓN, op. cit., pp. 573579. Aunque la Sentencia del TPI hablaba de una "deber de protección diplomática» de la Comisión, no se trata de protección diplomática, ni de protección o asistencia consulares, ni siquiera de protección funcional, ya que ni se plantea mediante la presentación de una reclamación formal para exigir responsabilidad internacional, ni los pescadores ejercen su labor como agentes por cuenta de la UE. La acción protectora es ejercida en base a la actividad profesional que esas personas desempeñan, la pesca, una actividad económica cuya regulación entra en la esfera de competencias de la UE y, por ello, es la UE y no los Estados quien celebra con terceros Estados los acuerdos de pesca que determinan las condiciones en que podrá ejercerse esa actividad y el interlocutor adecuado para exigir el cumplimiento de los mismos y efectuar, a través de sus delegaciones, las gestiones oportunas para proteger la actividad económica mediante la protección del individuo que la ejerce, CRESPO NAVARRO, op. cit., pp. 307-318.

42 La Comisión citó los casos de Abuja, Almaty, Ashgabat, Dar es Salaam, Pyongyang, Quito, Reikiavik, Minsk y Chisinau y recordó que en Dar es Salaam y Abuja las delegaciones de la Comisión ya compartían locales con algunos Estados miembros (cada parte posee y paga parte del edificio y los costes comunes se reparten de forma proporcional), sistema que valoraba positivamente al permitir un ahorro de costes y una mayor cooperación y suponer un reforzamiento de la protección de los ciudadanos, COM (2007) 767 final, pp. 10-11. En España, el art. 49 de la Ley 2/2014, de 25 de marzo de la Acción y del Servicio Exterior del Estado (BOE de 26 de marzo de 2014) prevé la posibilidad de que el Gobierno, a iniciativa del Ministerio de AA. EE. y Cooperación y a propuesta del Ministerio de Hacienda y Administraciones Públicas, y previo informe del Consejo Ejecutivo de Política Exterior, pueda acordar con los órganos competentes de la UE o de sus Estados miembros la creación de misiones diplomáticas conjuntas con otros miembros de la UE en terceros Estados, especialmente en los que no existan delegaciones de la UE; así como la incorporación de funcionarios españoles a delegaciones de la UE en los Estados en que España no tenga misión diplomática permanente, a fin de que desempeñen determinadas funciones del servicio exterior español, y que funcionarios del servicio exterior español compartan servicios comunes con las delegaciones de la UE o con las misiones diplomáticas 
oficinas comunes ${ }^{43}$, que actuarían de forma complementaria al sistema del Estado de referencia ${ }^{44}$.

\section{EL TRATADO DE LISBOA}

Tras la entrada en vigor del Tratado de Lisboa, la protección al ciudadano de la UE se recoge en el art. 20.2 c) y con más detalle en el art. $23 \mathrm{TFUE}^{45}$, prácticamente idéntico al antiguo art. $20 \mathrm{TCE}$ salvo en su párrafo segundo que dispone: «El Consejo podrá adoptar, con arreglo al procedimiento legislativo especial y previa consulta al PE, directivas en las que se establezcan las medidas de coordinación y de cooperación necesarias para facilitar dicha protección».

El Tratado de Lisboa tiene un valor añadido con respecto a la regulación anterior, al ofrecer por primera vez una base jurídica para el desarrollo normativo del derecho, otorgando a la Comisión la iniciativa en un procedimiento normativo especial en el que el papel del PE es de mera consulta. Además, la

permanentes de otros Estados miembros. Además, según el art. 50 de la Ley, el Gobierno, conforme al mismo procedimiento, podrá también acordar con otros miembros de la UE la creación de oficinas consulares conjuntas en terceros Estados, y compartir servicios comunes con las oficinas consulares de otros Estados de la UE, en particular en materia de visados Schengen.

Como propuso el Informe Barnier y recogió la Comisión en su Comunicación sobre la aplicación del Programa de La Haya, se comenzaría con una fase piloto en el Caribe, los Balcanes, el Índico y África Occidental. El PE, en su Resolución sobre el libro verde, reiteró su apoyo, que ya había manifestado en su Resolución sobre la diplomacia común comunitaria, de 5 de septiembre de 2000. También lo hizo el Comité Económico y Social, que no obstante llamó la atención sobre los posibles problemas jurídicos y defendió otras formas de colaboración alternativas como la representación consular, la colaboración en la protección por las delegaciones de la Comisión y el refuerzo del papel de la Comisión en la coordinación de las medidas adoptadas por los Estados miembros al respecto.

44 El concepto de Estado de referencia fue aprobado el 12 de junio de 2007 por el Comité Político de Seguridad del Consejo (Doc. 10715/07). Posteriormente el Consejo adoptó las Directrices de la UE para la aplicación del concepto de Estado de referencia en materia consular, DO C 317, de 12 de diciembre de 2008, pp. 6-8.

45 Conforme al primer párrafo: «Todo ciudadano de la Unión podrá acogerse, en el territorio de un tercer país en el que no esté representado el Estado miembro del que sea nacional, a la protección de las autoridades diplomáticas y consulares de cualquier Estado miembro, en las mismas condiciones que los nacionales de dicho Estado. Los Estados miembros tomarán las disposiciones necesarias y entablarán las negociaciones internacionales requeridas para garantizar dicha protección». 
Carta de Derechos Fundamentales de la UE ${ }^{46}$, a la que el Tratado de Lisboa dota del mismo rango jurídico que los Tratados, recoge en su art. 46 el derecho del ciudadano de la UE a acogerse a la protección de las autoridades diplomáticas y consulares de cualquier Estado miembro, lo que le confiere el carácter de derecho fundamental individual. Ahora bien, este derecho no se basa en un vínculo directo entre el ciudadano y la UE, por lo que no se reclama y ejerce ante la propia UE, sino ante los Estados miembros, a los que se impone una obligación respecto de los nacionales de los demás Estados miembros ${ }^{47}$. Es un derecho del ciudadano cuyo ejercicio queda sujeto a control jurisdiccional, de modo que la decisión de denegación de la protección podría ser objeto de recurso ante las autoridades judiciales competentes de los Estados miembros, pudiendo ser objeto de interpretación por el Tribunal de Justicia de la UE y, llegado el caso, generar la correspondiente responsabilidad por el perjuicio causado ${ }^{48}$.

Por su parte, el art. 35 TUE (antiguo art. 20 TUE) sigue recogiendo la obligación de las misiones diplomáticas y consulares de los Estados miembros y las delegaciones de la UE en terceros países ${ }^{49}$ y conferencias internacionales, $\mathrm{y}$ de sus representaciones ante las organizaciones internacionales de contribuir a la aplicación del derecho y de las medidas adoptadas en aplicación del art. 23 TFUE. Pero además, el art. 27.3 TUE prevé la puesta en funcionamiento de un SEAE, que fue efectivamente creado por Decisión 2010/427/UE del Consejo, de 26 de julio de $2010^{50}$, cuyo art. 5.10 establece que: «Las delegaciones de la Unión, de conformidad con el art. 35.3 TUE apoyarán a los Estados miembros, a petición de estos, en sus relaciones diplomáticas y en su función de prestación de protección consular a los ciudadanos de la Unión en terceros países, basándose en la neutralidad en lo que se refiere a los recursos».

Tras la entrada en vigor del Tratado de Lisboa, el Consejo Europeo de diciembre de 2009 aprobó el Programa de Estocolmo ${ }^{51}$, en el que volvía a

46 Carta de los Derechos Fundamentales de la UE, DO C 202, de 7 de junio de 2016, pp. 389-405.

47 MANGAS MARTÍN, loc. cit., pp. 734-736.

48 COM (2011) 149 final, ya citado, p. 5, que hace referencia al art. 47 de la Carta de Derechos Fundamentales de la UE (derecho a la tutela judicial efectiva y a un juez imparcial). GUZMÁN ZAPATER, loc. cit., p. 269.

49 Que conforme al art. 221.2 TFUE: «Actuarán en estrecha cooperación con las misiones diplomáticas y consulares de los Estados miembros».

50 DO L 201, de 3 de agosto de 2010, p. 30.

51 Programa de Estocolmo. Una Europa abierta y segura que sirva y proteja al ciudadano, DO C 115, de 4 de mayo de 2010, punto 2.7 titulado «Derecho a la protección en Estados no miembros». 
recalcar la falta de información suficiente de los ciudadanos sobre el derecho y la necesidad de continuar los esfuerzos para garantizar su plena aplicación, e invitaba a la Comisión a estudiar las medidas de coordinación y cooperación necesarias para lograrlo. La Comisión, en el plan de acción por el que se aplica el Programa de Estocolmo, propuso tres acciones concretas para cumplir ese cometido, a saber, presentar una comunicación sobre el balance y la futura evolución hacia una protección más eficaz; presentar una propuesta legislativa sobre la mejora de la compensación financiera para situaciones de crisis; y una propuesta de directiva sobre las medidas de coordinación y cooperación para facilitar la protección ${ }^{52}$.

En su sexto informe sobre la ciudadanía, la Comisión volvía a destacar la falta de efectividad plena del derecho, derivada en parte del desconocimiento, pero no solo de los ciudadanos sino también, en ocasiones, de los propios funcionarios consulares, e insistía en la necesidad de una coordinación eficaz y de cierto reparto de cargas entre los Estados miembros, que se había puesto de manifiesto en las crisis ocasionadas por los terremotos en Haití y Chile, o la nube volcánica de ceniza en Islandia. Y planteaba una acción concreta (acción 8$)^{\mathrm{a}}{ }^{53}$, que puso en marcha a través de una comunicación en que hacía balance de las medidas adoptadas en aplicación del plan de acción y presentaba la perspectiva futura $^{54}$, enfocada en tres aspectos principales. En primer lugar, incrementar la sensibilización, mediante acciones de comunicación y de formación e intercambio de buenas prácticas para los funcionarios consulares. En segundo lugar, presentar propuestas legislativas con base en las disposiciones del Tratado de Lisboa para establecer medidas de coordinación y cooperación, y seguir promoviendo la inclusión de cláusulas de consentimiento en los acuerdos mixtos y en los bilaterales. En tercer lugar, mejorar la distribución de los costes y la utilización optimizada de los recursos, sobre todo en situaciones de crisis, abordando la posibilidad de establecer una compensación financiera para tales casos.

El mismo día, la Comisión abrió un sitio web específico en la página Europa, facilitó el acceso de los ciudadanos a Europe direct, servicio telefónico que proporciona información general sobre los derechos en la UE, incluyendo

52 Comunicación de la Comisión al PE, al Consejo, al Comité Económico y Social y al Comité de las Regiones, Garantizar el espacio de libertad, seguridad y justicia para los ciudadanos europeos. Plan de acción por el que se aplica el Programa de Estocolmo, COM (2010) 171 final, 20 de abril, p. 17.

53 En dicho informe presentó un total de 25 acciones para mejorar la vida cotidiana de los ciudadanos de la UE, sexto informe sobre la ciudadanía, La eliminación de los obstáculos a los derechos de los ciudadanos de la UE, COM (2010) 603 final, de 27 de octubre, punto 2.1.6.

54 COM (2011) 149 final, de 23 de marzo ya citada. 
este tipo de protección ${ }^{55}$, y, unos meses más tarde, el 14 de diciembre de 2011, adoptó una propuesta de directiva sobre la protección consular para los ciudadanos de la UE en el extranjero ${ }^{56}$.

\section{LA DIRECTIVA (UE) 2015/637 SOBRE LAS MEDIDAS DE COORDINACIÓN Y COOPERACIÓN PARA FACILITAR LA PROTECCIÓN DE LOS CIUDADANOS DE LA UNIÓN NO REPRESENTADOS EN TERCEROS PAÍSES}

\section{CONTEXTO Y FUNDAMENTO}

La Directiva fue aprobada el 20 de abril de 2015 por votación en el seno del Consejo ${ }^{57}$ conforme a un procedimiento legislativo especial, a partir de una propuesta de la Comisión y previo dictamen del $\mathrm{PE}^{58}$. La Comisión fundamentó su propuesta en la ausencia de acuerdo sobre el contenido del derecho

55 Ver respuesta de la Comisión de 1 de junio de 2011, a la pregunta parlamentaria núm. E-2795/2011, de 22 de marzo. La web http://ec.europa.eu/consularprotection dedicada a la protección, contiene información general, las direcciones de las representaciones diplomáticas y consulares de los Estados miembros en países terceros y acceso a las recomendaciones de viaje de los Estados miembros. Ver también nexo I: «Seguimiento del Informe de 2010 sobre la ciudadanía de la UE: 25 acciones realizadas» del informe sobre ciudadanía de la UE 2013, Ciudadanos de la Unión: vuestros derechos, vuestro futuro, COM (2013) 269 final, de 8 de mayo, p. 34; y COM (2011) 149 final, p. 11

56 Propuesta de Directiva del Consejo relativa a la protección consular de los ciudadanos de la Unión en países extranjeros, COM (2011) 881 final, de 14 de diciembre. Puede verse un análisis de la propuesta de Directiva en J. Jorge PIERNAS LÓPEZ, «La protección diplomática y consular de los ciudadanos de la Unión Europea tras el Tratado de Lisboa», Revista de Derecho Comunitario Europeo, núm. 48, (2014), pp. 577-599, pp. 583-599; del mismo autor "Ciudadanía y acción exterior de la Unión», en Cesáreo GUTIÉRREZ ESPADA, y Ma José CERVELL HORTAL, La Unión Europea como actor global de las relaciones internacionales. Retos y problemas seleccionados, Valencia, 2016, pp. 273-306.

57 Con 26 votos a favor y la abstención del Reino Unido y la República Checa, Doc. 8155/15 del Consejo, de 21 de abril de 2015.

58 Resolución legislativa del PE, de 25 de octubre de 2012, sobre la Propuesta de Directiva del Consejo relativa a la protección consular de los ciudadanos de la UE en países extranjeros, DO C 72 E, de 11 de marzo de 2014, pp. 101-117. Pueden verse los comentarios de los Gobiernos sobre dicha propuesta en Doc. 15677/13 del Consejo de 12 de noviembre de 2013. 
y sobre las obligaciones concretas que acarrea, y en la falta de uniformidad entre las leyes y prácticas consulares de los Estados miembros al respecto ${ }^{59}$, destacando como objetivo principal aclarar el contenido del derecho y simplificar la cooperación y coordinación entre las autoridades consulares. Para lograrlo, la propuesta aborda, en particular, cuatro áreas específicas.

En primer lugar, el ámbito personal del derecho, los beneficiarios de la protección. Se requiere aclaración sobre cuándo un Estado miembro carece de representación y en qué medida la protección puede extenderse a los familiares del ciudadano de la UE nacionales de terceros Estados.

En segundo lugar, el acceso a la protección y la cooperación y coordinación entre Estados miembros. Ha de determinarse qué Estado debe ejercer la protección, pues aunque el Tratado deja libertad de elección al ciudadano, en la práctica los Estados pueden llegar a acuerdos para el reparto de cargas que, en opinión de la Comisión, son aceptables siempre que se garantice una protección eficaz y la suficiente publicidad para que el ciudadano pueda conocerlos. Debe asimismo mejorar la cooperación y coordinación entre el Estado que presta la asistencia y el de nacionalidad.

En tercer lugar, la coordinación local. Las autoridades consulares presentes en el tercer país han de estar en contacto y disponer de información que no se recoge sistemáticamente (sobre ciudadanos no representados, datos de contacto de las autoridades de los Estados miembros sin representación, traductores, abogados, médicos que hablen la lengua de los ciudadanos no representados...). Además, aunque el art. 35 TUE establece que las delegaciones de la UE deben contribuir al ejercicio del derecho, no se determinan las respectivas esferas de competencia ni el ámbito de actuación.

Por último, ha de perfeccionarse la coordinación en situaciones de crisis y simplificarse los procedimientos de reembolso de los gastos ocasionados para fomentar un enfoque proactivo hacia los ciudadanos no representados. Entre los principales problemas detectados, la Comisión señala que no está claro quién debe asistir a los ciudadanos no representados en situación de crisis, ni cuál es el papel del Estado principal, y también que los planes de contingencias no suelen atender específicamente a los ciudadanos no representados, cuyo número es difícil de determinar en situación de crisis; que en crisis graves

59 Ausencia de uniformidad que se puso de manifiesto en el informe de diciembre de 2010 Consular and diplomatic protection. Legal Framework in the EU Member States, elaborado por el Citizens Consular Assistance Regulation in Europe (CARE) Project, con la subvención del Programa de Derechos Fundamentales y Ciudadanía de la Comisión Europea (en adelante CARE Project). También destacada por la doctrina, GUTIÉRREZ ESPADA, loc. cit., pp. 86-87; y REY ANEIROS, loc. cit., pp. 22-23. 
el personal local puede necesitar apoyo de especialistas en intervención de crisis y esa posibilidad no está regulada. Y, finalmente, que los procedimientos genéricos de reembolso de gastos previstos en la Decisión 95/553/CE y en las Directrices consulares no suelen aplicarse en situaciones de crisis, al no ajustarse a las necesidades específicas que están en juego en esos casos, como la alta presión del momento o el elevado número de ciudadanos a los que prestar ayuda.

En definitiva, la Directiva trata de mejorar y completar la regulación que ofrece de forma muy limitada la Decisión 95/553/CE a la que deroga, incluyendo además los aspectos de la coordinación y cooperación entre Estados miembros, especialmente en situación de crisis, hasta ahora recogidos en parte en la Directrices sobre protección consular aprobadas por el Consejo, delimitando el papel de las delegaciones de la UE y simplificando los procedimientos financieros para el reembolso de los gastos.

\section{ESTRUCTURA}

El texto de la Directiva finalmente aprobada por el Consejo se estructura en cuatro capítulos y se compone de un total de 21 arts. El capítulo 1 (arts. 1 a 9) especifica su objeto y ámbito de aplicación y recoge las disposiciones generales sobre la protección. El capítulo 2 (arts. 10 a 13) incluye las medidas de coordinación y cooperación necesarias para garantizar la protección, refiriéndose al papel de las delegaciones de la UE, a la cooperación local y a la cooperación especial en caso de crisis. El capítulo 3 (arts. 14 y 15) contiene las disposiciones sobre los procedimientos financieros aplicables, distinguiendo entre un procedimiento general y otro simplificado para situaciones de crisis. Por último, el capítulo 4 introduce las «disposiciones finales» (arts. 16 a 21) sobre trato más favorable, trasposición ${ }^{60}$, derogación de la Decisión 95/553/ $\mathrm{CE}$, informe, evaluación y revisión, entrada en vigor y destinatarios.

La Directiva se completa con dos anexos. El anexo I incluye los formatos comunes de compromiso de devolución de los gastos de protección consular para el caso de asistencia económica y para el caso de repatriación, que deberán cumplimentar los ciudadanos no representados de conformidad con el art. 14.1 de la Directiva. El anexo II recoge el formulario de solicitud de reembolso que deberá cumplimentar el Estado miembro que preste la protección y dirigir al Estado miembro del que el ciudadano sea nacional, de conformidad con el art. 14. 2 de la Directiva.

60 El art. 17 fija como fecha tope para la trasposición el 1 de mayo de 2018. 


\section{OBJETO Y ÁMBITO DE APLICACIÓN}

La Directiva tiene por objetivo (art. 1) establecer las medidas de coordinación y cooperación necesarias para facilitar el ejercicio del derecho de los ciudadanos de la UE de acogerse, en el territorio de un país en el que no esté representado el Estado miembro de su nacionalidad, a la protección de las autoridades diplomáticas y consulares de cualquier Estado miembro en las mismas condiciones que los nacionales de dicho Estado, teniendo también en cuenta el papel de las delegaciones de la UE para contribuir a la aplicación del derecho $^{61}$. Se persigue que tales medidas, que constituyen normas mínimas ${ }^{62}$, aumenten la seguridad jurídica y una cooperación y solidaridad eficaces entre las autoridades consulares.

El apartado segundo del art. 1 establece que la Directiva no afecta a las relaciones consulares entre Estados miembros y terceros Estados. Se refiere a los derechos y obligaciones derivados de los usos y acuerdos internacionales, especialmente, a la posibilidad de ejercer funciones consulares por cuenta de otro Estado prevista en el art. 8 de la Convención de Viena sobre relaciones consulares de 1963, previa notificación y siempre que el tercer país afectado no se oponga ${ }^{63}$.

Ahora bien, el considerando 6 de la Directiva señala que los Estados miembros, con el apoyo de la cooperación consular local, deben emprender ante los terceros países las gestiones necesarias para que se pueda proporcionar protección en nombre de otros Estados miembros en cualquier circunstancia.

61 Conviene llamar la atención sobre la terminología utilizada. Es la primera vez que se utiliza expresamente el término «derecho». La Comisión proponía la expresión «derecho a la protección» y el PE en su Resolución suprimía el término «derecho» para hablar de «la protección por parte de las autoridades diplomáticas y consulares» (enmienda 25). Finalmente se recogió la fórmula «derecho de acogerse a la protección de las autoridades diplomáticas y consulares».

62 El art. 16 de la Directiva señala que los Estados miembros podrán introducir o mantener disposiciones más favorables que las contenidas en la Directiva siempre que sean compatibles con ellas.

63 En el caso de España, en virtud del art. 7 del Tratado de buena vecindad, amistad y cooperación entre el Reino de España, la República francesa y el Principado de Andorra: «En los Estados en los que el Principado de Andorra no dispone de representación consular, y sin perjuicio de las disposiciones del derecho internacional que regulen las relaciones diplomáticas y consulares, así como del acuerdo de los citados Estados, los nacionales andorranos podrán acudir, en caso de necesidad, bien a una oficina consular del Reino de España, bien a una oficina consular de la República Francesa, en la medida en que ambas coexistan», BOE, de 30 de junio de 1993. 
Merece la pena recordar, en este sentido, la labor de la Comisión como impulsora de la inclusión de cláusulas de consentimiento en los acuerdos bilaterales celebrados por los Estados miembros y en los acuerdos mixtos celebrados por la UE y sus Estados miembros con terceros Estados.

La práctica de los Estados en esta materia es muy escasa ${ }^{64} \mathrm{y}$, por lo que se refiere a los acuerdos mixtos, pueden citarse ya algunos ejemplos, como el Acuerdo de colaboración y cooperación reforzadas con la República de Kazajistán, cuyo art. 239 titulado "protección consular» dispone: «La República de Kazajistán conviene en que las autoridades diplomáticas y consulares de cualquier Estado miembro de la Unión Europea representado en la República de Kazajistán proporcionará protección a cualquier nacional de un Estado miembro de la Unión Europea que no disponga de una representación permanente accesible en la República de Kazajistán, en las mismas condiciones que a los nacionales de aquel Estado miembro de la Unión Europea» ${ }^{65}$.

Los acuerdos con Nueva Zelanda y Australia incluyen también estas cláusulas, pero en otros términos. Así, el art 39 del Acuerdo Marco entre la UE y sus Estados miembros, por una parte, y Australia, por otra dispone:

1. Australia acepta que las autoridades diplomáticas y consulares de cualquier Estado miembro representado en Australia puedan ejercer la protección consular en nombre de otros Estados miembros que no dispongan de representación permanente accesible en Australia.

2. La Unión y los Estados miembros aceptan que las autoridades diplomáticas y consulares de Australia puedan ejercer la protección consular en nombre de un tercer país y que terceros países puedan ejercer la protección consular en nombre de

64 Solo Italia y Portugal incluyen este tipo de cláusulas en acuerdos con terceros Estados, mientras que la mayoría de Estados miembros se limita a notificar a los terceros Estados que ejercerá la asistencia, llegado el caso, GUTIÉRREZ ESPADA, loc. cit., p. 87; ver también CARE Proyect, ya citado.

65 Acuerdo de colaboración y cooperación reforzadas entre la UE y sus Estados miembros, por una parte, y la República de Kazajistán, por otra, DO L 29, de 4 de febrero de 2016. Similares son las cláusulas en la Propuesta de Acuerdo con Afganistán (art. 29), ver anexo de la Propuesta Conjunta de Decisión del Consejo relativa a la firma en nombre de la UE y a la aplicación provisional del Acuerdo de Cooperación sobre Asociación y Desarrollo entre la UE y la República Islámica de Afganistán (Doc. 12507/16 del Consejo, de 23 de septiembre de 2016); y con Malasia (art. 21), ver anexo de la Propuesta Conjunta de Decisión del Consejo relativa a la firma, en nombre de la UE, del Acuerdo Marco de Colaboración y Cooperación entre la UE y el Gobierno de Malasia (Doc. 11644/16 Add.1, de 5 de agosto de 2016). 
Australia en la Unión en lugares en los que Australia o el tercer país de que se trate no dispongan de representación permanente accesible.

3. Los apartados 1 y 2 eliminan cualquier requisito de notificación o autorización que de otro modo pudiera aplicarse.

4. Las partes convienen en facilitar el diálogo sobre asuntos consulares entre sus respectivas autoridades competentes ${ }^{66}$.

Por otra parte, la Directiva trata de aclarar, en su art. 4, qué debe entenderse por ciudadano no representado. Lo será todo ciudadano que tenga la nacionalidad de un Estado miembro que carezca de representación conforme al art. 6, el cual determina que se considerará que un Estado miembro no está representado en un tercer país, tanto si carece allí de embajada o consulado establecidos con carácter permanente, como si carece de embajada, consulado o cónsul honorario que esté en disposición de proporcionar protección consular de manera efectiva en un caso determinado ${ }^{67}$. Ello ocurriría si la

66 Se aclara además en nota a pie que Australia acepta el uso del término "protección consular» en este artículo, en lugar del término "funciones consulares», a condición de que comprenda las funciones a que se refiere el art. 9 de la Directiva (UE) 2015/637 del Consejo y que estas funciones incluyan la expedición de pasaportes y/o documentos de viaje de urgencia (Doc. 9776/16, de 5 de julio de 2016). Ver también la Decisión del Consejo relativa a la firma, en nombre de la UE, y a la aplicación provisional del Acuerdo Marco entre la UE y sus Estados miembros, por una parte, y Australia por otra-Adopción, pendiente de aprobación como punto A del Consejo en sus próximas sesiones, Doc. 11836/16, de 21 de septiembre de 2016. Idéntico es el art. 36 del Acuerdo de Asociación sobre Relaciones y Cooperación entre la UE y sus Estados miembros, por una parte, y Nueva Zelanda, por otra (salvo que no incluye aclaración terminológica sobre el concepto de protección consular), Doc. 9787/16, de 2 de agosto de 2016. Véase también la Decisión del Consejo relativa a la firma, en nombre de la UE, y la aplicación provisional del Acuerdo de Asociación sobre Relaciones y Cooperación entre la UE y sus Estados miembros, por una parte, y Nueva Zelanda, por otra-Adopción, (Doc. 11845/16, de 21 de septiembre de 2016), pendiente de aprobación como punto A del Consejo en sus próximas sesiones.

67 La Decisión 95/553/CE exigía que no hubiera ni representación permanente «accesible», ni cónsul honorario "accesible y competente». Según las Directrices para la aplicación complementaria de una serie de disposiciones de la Decisión 95/553/CE, ya citadas por «representación permanente y accesible», debía entenderse aquella a la que un ciudadano pueda llegar de manera segura por tierra (carretera o ferrocarril) en tiempo razonable y que se encuentre a una distancia conveniente, en función de las circunstancias específicas existentes en el tercer país en cuestión (criterio también aplicable a los cónsules honorarios), y por "cónsules honorarios accesibles y competentes», los que estén facultados, como mínimo, para expedir documentos provisionales de 
embajada, consulado o cónsul honorario establecido es incapaz, por cualquier circunstancia, de proporcionar en un caso determinado la protección a la que tendría derecho la persona afectada de acuerdo con el derecho o la práctica nacionales ${ }^{68}$. Los ciudadanos que tengan la nacionalidad de más de un Estado miembro deben considerarse no representados si ninguno de los Estados miembros de nacionalidad está representado en el tercer país en cuestión.

Otra cuestión que aborda la Directiva es si los cónsules honorarios pueden proporcionar este tipo de asistencia. Teniendo en cuenta que estos con frecuencia ejercen sus funciones de forma voluntaria y que sus competencias varían en las diferentes legislaciones y prácticas nacionales, el art. 2.2 deja a los Estados miembros la decisión de si la Directiva se les aplica o no. Pero deberán informar a los ciudadanos no representados de dicha decisión y, en su caso, de la medida en la que los cónsules honorarios serán competentes para proporcionar protección en un caso determinado ${ }^{69}$.

viaje y facilitar socorro y repatriación de ciudadanos en dificultades. La Propuesta de Directiva de la Comisión utilizaba también el término «accesible», pero lo concretaba en la posibilidad de prestar una protección efectiva y poder llegar a la representación con seguridad tras un trayecto y tiempo de viaje razonables (ida y vuelta en el mismo día por medios habituales de transporte, salvo que la urgencia requiriera una protección más rápida), y especificaba que si la embajada o consulado no pudieran prestar protección efectiva, especialmente si estuvieran cerrados temporalmente por situación de crisis, se considerarían no accesibles.

68 En ese sentido, las embajadas y los consulados deben comunicarse mutuamente cualquier circunstancia excepcional que pueda afectar temporalmente a su capacidad de proporcionar la asistencia. Deben tenerse en cuenta a esos efectos la accesibilidad y la proximidad. El ciudadano solicitante no puede ser reenviado a la embajada o al consulado del Estado miembro del que es nacional si, a causa de la situación local o de la falta de recursos, no puede contactar o ser contactado de manera segura por su embajada, consulado o cónsul honorario de un modo que le permita recibir la asistencia (considerando núm. 8).

69 En España, el Real Decreto 1390/2007, de 29 de octubre, por el que se aprueba el Reglamento de los Agentes consulares honorarios de España en el extranjero, dispone en su art. 14: «1. Los agentes consulares honorarios actuarán como auxiliares o delegados del funcionario de carrera del que dependan. Por tanto, sus atribuciones estarán en cada caso determinadas por las instrucciones que de éste reciban. 2. En el ejercicio de sus funciones estarán especialmente facultados para prestar, en conexión con la Oficina consular de carrera o, en su caso, de la Misión Diplomática de la que dependa, la asistencia y protección consular debida a los nacionales españoles. 3. En todo momento dichas facultades o atribuciones podrán ser ampliadas o reducidas de acuerdo con las necesidades del servicio, sin otras limitaciones que las establecidas por la Ley y los Tratados internacionales [...]», BOE de 13 de noviembre de 2007, pp. 
Aunque no estaba previsto en la propuesta de la Comisión, el art. 3 reconoce expresamente la posibilidad de que sea el Estado miembro de nacionalidad del solicitante el que conceda la protección de acuerdo con su derecho y práctica nacionales, a pesar de no estar representado, por ejemplo, prestando servicios consulares en línea, siempre que eso no suponga privar de protección al ciudadano no representado. A ese fin, el Estado de nacionalidad podrá solicitar al Estado miembro al que el ciudadano haya pedido la protección, o del que ya la esté recibiendo, que le reenvíe la solicitud o el caso, y dicho Estado deberá renunciar al mismo, cuando el Estado miembro de nacionalidad confirme que está protegiendo al ciudadano.

Los beneficiarios de la protección son los ciudadanos de la UE no representados, cuyo derecho se reconoce en el TFUE, y en la Carta de Derechos Fundamentales de la UE. Pero, además, el art. 5 de la Directiva extiende la protección a los familiares del ciudadano no representado que no sean ellos mismos ciudadanos de la UE cuando el Estado miembro en cuestión la proporcionaría, de conformidad con su derecho o prácticas nacionales, a los familiares de sus nacionales, y debe proporcionarla en la misma medida y en las mismas condiciones que lo haría en tales casos. Cabe incluso que los Estados miembros implicados (Estado protector y Estado de nacionalidad) acuerden, durante las consultas que deben tener entre ellos antes de que se preste la protección, extenderla a los familiares más allá de lo exigido por el derecho o la práctica nacional, siempre que lo pactado sea conforme con el derecho de la UE ${ }^{70}$.

Conviene advertir que la Comisión había también valorado la posibilidad de que se ofreciera la protección a los refugiados y a los residentes de larga duración, pero entendió que ello suponía alejarse demasiado del marco

46378-46382. La práctica española al respecto es restrictiva. Los cónsules honorarios no proporcionan protección ni asistencia consular, salvo de manera puntual, según las instrucciones que reciban del cónsul del que dependan. Por tanto, en principio, no les será de aplicación la Directiva (información oficiosa obtenida de la DG de Españoles en el Exterior y de Asuntos Consulares y Migratorios).

70 Considerando núm. 9, que aclara que los Estados miembros pueden no estar en disposición de prestar determinados tipos de protección a los miembros de la familia nacionales de terceros países, por ejemplo, expedición de documentos provisionales de viaje. No se limita, sin embargo, el concepto de familiar de ciudadano de la UE, a pesar de que la Comisión en su propuesta incluía una remisión a los arts. 2 y 3 de la Directiva 2004/08/CE del PE y del Consejo, de 29 de abril de 2004, relativa al derecho de los ciudadanos de la UE y de los miembros de sus familias a circular y residir libremente en el territorio de los Estados miembros ( $D O \mathrm{~L} \mathrm{158,} \mathrm{de} 30$ de abril de 2004) como inspiración de cualquier precisión al respecto. Remisión que el PE mantuvo en su Resolución. 
establecido y consideró que era prematuro en el momento actual, por lo que no lo recogió en su propuesta ${ }^{71}$. En cambio, el PE en su Resolución sobre la propuesta de la Comisión, en línea con sus posiciones anteriores, propuso introducir un nuevo considerando que recogiera el deber del Estado que presta la protección de valorar la posibilidad de proporcionarla también, teniendo en cuenta su situación concreta, a refugiados, apátridas y otras personas que no siendo nacionales de ningún Estado miembro, residen en un Estado miembro y poseen un documento de viaje expedido por él.

A la identificación de los solicitantes se refiere el art. 8. Al ciudadano de la UE se le exige prueba de la nacionalidad mediante la presentación de un pasaporte o documento de identidad, salvo que no sea posible presentar tales documentos, en cuyo caso podrá demostrar la nacionalidad por otros medios y, si es necesario, mediante comprobación ante las autoridades diplomáticas o consulares del Estado miembro del que declare ser nacional ${ }^{72}$. Los familiares del ciudadano, podrán probar la existencia y el tipo de relación familiar por cualquier medio, incluida también la comprobación ante las autoridades diplomáticas o consulares del Estado de nacionalidad del ciudadano.

\section{CONTENIDO}

La Directiva menciona expresamente distintas situaciones tipo en las que todos los Estados miembros conceden protección a sus propios nacionales en función de las circunstancias particulares de cada caso ${ }^{73}$. Pero, dado que la protección requerida depende siempre de situaciones concretas, no se limita solo a esos supuestos. Según el art. 9 la protección podrá comprender, entre otras cosas, la asistencia en caso de:

a) detención o prisión;

b) ser víctima de un delito $^{74}$;

71 Documento de trabajo de los servicios de la Comisión que contiene el resumen de la evaluación de impacto que acompaña a la Propuesta de Directiva, Doc. 18821/11, Add.1, de 19 de diciembre de 2011.

72 Como recuerda el considerando núm. 13 la condición de ciudadano de la UE la otorga directamente el derecho de la UE, por lo que el valor de los documentos probatorios es meramente declarativo.

73 Ver al respecto el documento Prácticas comunes en materia de asistencia consular y coordinación de crisis, elaborado por el COCON del Consejo, Doc. 10698/10, de 9 de junio de 2010.

74 La Decisión de 95/553/CE se refería las «víctimas de actos de violencia». Ahora no se exige que el delito sea violento. 
c) accidente grave o enfermedad grave;

d) fallecimiento;

e) ayuda y repatriación en caso de emergencia;

f) necesidad de documentos provisionales de viaje como dispone la Decisión 96/409/PESC.

No se detalla el contenido de la protección que deberán conceder los Estados miembros en cada uno de esos supuestos, a diferencia de lo que ocurría en la propuesta presentada por la Comisión, que dedicaba un art. específico para cada caso concretando en líneas generales el tipo de ayuda o asistencia a ofrecer. Pero sí se prevé la conveniencia de respetar, cuando proceda, los deseos del ciudadano, por ejemplo, sobre si debe informarse a sus familiares $\mathrm{u}$ otras personas allegadas y de ser así a quién, y, en caso de fallecimiento del ciudadano, los deseos de su familiar más próximo acera de las decisiones a tomar sobre los restos mortales ${ }^{75}$.

Respecto a cómo deba llevarse a cabo la protección, el art. 2.1 establece, como principio general, la obligación de las embajadas o consulados de los Estados miembros de proporcionarla a los ciudadanos no representados en las mismas condiciones que a sus propios nacionales, por lo que el derecho deberá garantizarse sin discriminación por razón de nacionalidad, debiendo interpretarse a la luz del art. 18 TFUE y del art. 21 de la Carta de Derechos Fundamentales de la $\mathrm{UE}^{76}$. En todo caso, la Directiva no afecta a la competencia de los Estados para definir el alcance de la protección que prestan a sus propios nacionales ${ }^{77}$ que, como ya hemos destacado, varía de un Estado a otro.

\section{ACCESO A LA PROTECCIÓN Y COOPERACIÓN ENTRE LOS ESTADOS MIEMBROS Y CON LA UNIÓN EUROPEA}

Otro aspecto que debía abordarse era el del acceso a la protección y la cooperación y coordinación entre los Estados implicados para hacerla efectiva.

\footnotetext{
75 Considerando núm. 15.

76 Según el considerando núm. 14, los Estados miembros deben aplicar también la Directiva sin discriminación por razón de sexo, raza, color, origen étnico o social, características genéticas, lengua, religión o convicciones, opiniones políticas o de cualquier otro tipo, pertenencia a una minoría nacional, patrimonio, nacimiento, discapacidad, edad u orientación sexual.

77 Considerando núm. 5.
} 
Por un lado, debía determinarse dónde puede el ciudadano no representado solicitar la protección ${ }^{78}$. El art. 7 aclara que los ciudadanos no representados deberán tener derecho a solicitarla a la embajada o el consulado de cualquier Estado miembro. Sin embargo, ello no impedirá que un Estado miembro pueda representar a otro de manera permanente y que las embajadas o consulados de los Estados miembros puedan, cuando lo estimen necesario, alcanzar acuerdos prácticos sobre el reparto de responsabilidades para prestar la protección a ciudadanos no representados ${ }^{79}$. Eso sí, los Estados miembros habrán de informar a la Comisión y al SEAE de cualquier acuerdo, al que tanto la UE como los Estados miembros darán publicidad. Además, cuando se haya alcanzado un acuerdo de ese tipo y como consecuencia del mismo la embajada o consulado a la que se dirige el ciudadano no representado no sea competente para protegerlo, deberá asegurarse de que la solicitud del ciudadano sea redirigida a la embajada o consulado pertinente, salvo que la protección se vea comprometida, y la urgencia del caso requiera una intervención inmediata por su parte.

Por otro lado, las medias de coordinación y cooperación. En concreto, el art. 10 establece las normas generales que exigen una estrecha cooperación y coordinación entre las autoridades diplomáticas y consulares de los Estados miembros y con la UE para garantizar la protección a los ciudadanos no representados. Tales normas prevén que el Estado miembro que reciba la solicitud de protección o sea informado de una situación de emergencia individual, consulte sin demora con el Ministerio de AA. EE. o, en su caso, con la embajada o consulado competente del Estado miembro de nacionalidad del ciudadano en dificultades, y le proporcione toda la información pertinente de la que disponga (identidad del afectado, posibles gastos de la protección y familiares a los que se puede ampliar la protección.... ${ }^{80}$. Consultas que, salvo extrema urgencia, tendrán lugar con carácter previo. El Estado miembro que

78 Antes incluso de la adopción de la Decisión 553/95/CE, E. Vilariño planteaba esa cuestión, que entendía debía resolverse por la vía de acuerdos entre los Estados, VILARIÑO PINTOS, «Representación exterior y cooperación...», loc. cit., pp. 438-439.

79 El art. 4 de la Decisión 553/95/CE ya tenía en cuenta la existencia de este tipo de acuerdos, al afirmar que, sin perjuicio de la aplicación del art. 1, las representaciones diplomáticas y consulares podrían convenir acuerdos prácticos que permitan la gestión eficaz de la solicitudes de protección. Pueden verse los acuerdos existentes entre algunos Estados miembros en CARE Project, ya citado.

80 La Decisión 553/95/CE solo exigía esa comunicación en caso de anticipo, ayuda económica o gasto que, salvo caso de extrema urgencia, no podía concederse o comprometerse sin la previa autorización de las autoridades del Estado de nacionalidad (art. 6). 
preste la protección facilitará el intercambio de información entre el ciudadano afectado y las autoridades del Estado de su nacionalidad. Y este último, si se le solicita (a través del Ministerio de AA. EE., o de la embajada o consulado competente) deberá remitir al Estado que protege a su ciudadano toda la información pertinente sobre el caso, y será responsable de entablar los contactos necesarios con los familiares u otras personas o autoridades ${ }^{81}$.

También se aclara el papel de las delegaciones de la UE. El art. 11 de la Directiva reconoce expresamente que las delegaciones de la UE cooperarán estrechamente con las embajadas y consulados de los Estados miembros y se coordinarán con ellas para contribuir a la cooperación y la coordinación locales y en caso de crisis y se especifica el contenido de esa cooperación. En particular, las delegaciones de la UE proporcionarán el apoyo logístico disponible, como espacio de oficinas y equipamiento organizativo, por ejemplo, alojamiento temporal para el personal consular y los equipos de intervención $^{82}$. Además, junto con la sede central del SEAE facilitarán el intercambio de información entre las embajadas y consulados de los Estados miembros y, cuando proceda, con las autoridades locales. Asimismo facilitarán la información general disponible sobre la protección a la que podrían tener derecho los ciudadanos no representados y sobre los acuerdos prácticos alcanzados entre los Estados.

No se incluye ninguna referencia a una posible acción protectora de la propia UE. A pesar de haber planteado en el libro verde y el plan de acción posterior esa posibilidad, la Comisión, consciente de que la responsabilidad de la asistencia y protección de los ciudadanos en el extranjero sigue recayendo

81 A esos efectos, los Estados miembros han de informar al SEAE (mediante Consular On Line) de los puntos de contacto en los respectivos Ministerios de AA. EE.

El informe especial núm. 11 del Tribunal de Cuentas Europeo sobre La instauración del Servicio Europeo de Acción Exterior de 2014, destaca en su observación núm. 63 que el nuevo papel de las delegaciones de la UE no ha ido acompañado de una explotación significativa de las sinergias con los servicios diplomáticos de los Estados miembros, lo que entiende podría achacarse al escaso tiempo transcurrido y a la falta de compromiso de los Estados; y añade que la coubicación sigue siendo muy limitada y la información política común es excepcional. El SEAE responde a esa observación que junto a los cuatro proyectos de utilización común de instalaciones en marcha, desde la creación del SEAE, se han iniciado otros ocho proyectos en siete terceros Estados y se están estudiando otros más, y que confía en que esta práctica se consolidará, pues la utilización común de instalaciones es una prioridad para el SEAE, no solo por motivos prácticos y económicos, sino también por su valor simbólico. 
principalmente sobre los Estados miembros ${ }^{83}$, se limitó en la propuesta de Directiva a recoger la mera cooperación de las delegaciones de la UE al respecto $^{84}$. En cambio, el PE fue más allá en su Resolución sobre la propuesta

83 En ese sentido, el Ministro de AA. EE. belga el 23 de agosto de 2010, a la pregunta de un diputado sobre la implicación de la UE en las negociaciones para liberar a un militar franco-israelí secuestrado por un comando militar palestino, tras señalar que la UE no se había implicado en las negociaciones, pero sí había apelado en numerosas ocasiones al respeto del derecho internacional, al acceso del CICR y a su liberación, afirmó: «L’assistance consulaire est une compétence exclusivement nationale. La défense des intérêts d'otages européens est de la prérogative des États membres concernés. L'Union européenne ne développe donc pas de politique spécifiquement concernant les négociations d'otages européens. Rien de tel n'est prévu en outre dans les textes qui fondent les compétences du SEAE qui est en train d'être mis en place", «Pratique du Droit International Public», RBDI, vol. 67, núm. 2, 2014, p. 599.

El informe de revisión del SEAE de la antigua alta representante para AA. EE. y Política de Seguridad, C. Ashton, de julio de 2013, destacaba que, sin perjuicio del debate político en los Estados miembros sobre si el SEAE debía abarcar competencias nacionales en materia de protección consular, el SEAE dispone de momento de recursos muy limitados en este ámbito (concentrados en la coordinación de las medidas de respuesta en caso de crisis) y carece de recursos o conocimientos técnicos especializados en las delegaciones y que, si bien la Decisión de creación de SEAE apunta a un futuro papel de las delegaciones de la UE en la protección consular de los ciudadanos de la UE, ello solo podría lograrse si los recursos y conocimientos se transfieren desde los Estados miembros. Además, según la observación núm. 64 del informe especial núm. 11 del Tribunal de Cuentas Europeo: «El Tratado de Lisboa, que estableció las delegaciones de la UE, aumentó las expectativas de que las 'casas de Europa' proporcionaran servicios consulares, entre ellos, la protección consular de los ciudadanos de la UE. Sin embargo, aún queda mucho por hacer y el SEAE todavía no ha elaborado un análisis detallado de las implicaciones financieras de ocuparse de estas cuestiones, especialmente de satisfacer las expectativas de algunos Estados miembros pequeños y de tamaño intermedio. Los Estados miembros tampoco han llegado a una posición común sobre este asunto ni han alcanzado un acuerdo sobre la armonización de normas y legislación aplicables en caso de crisis y de emergencia, la formación del personal y la distribución de los costes». El SEAE contestó: «Cabe recordar que la protección consular sigue siendo competencia nacional, por lo que las delegaciones no ofrecen asistencia directa a los ciudadanos de la UE. Las delegaciones dan apoyo a los Estados miembros facilitando la cooperación y ayudándolos a ofrecer asistencia a ciudadanos que no están representados. Esto se hace en una serie de países. Un ejemplo reciente es Sudán del Sur, donde la delegación ayudó a coordinar localmente la evacuación de ciudadanos que carecen de representación (principales países cuyos nacionales carecen de representación: Italia, Bélgica, Finlandia, 
planteando que las delegaciones de la UE prestasen directamente, en caso necesario, la protección a los ciudadanos no representados en dificultades y no solo su cooperación a los Estados en situaciones de crisis ${ }^{85}$.

La implicación de la UE en la protección de los ciudadanos de la UE en terceros Estados en apoyo de la acción llevada a cabo por el Estado de nacionalidad no es una novedad. Ya nos hemos referido a la práctica de protección por afinidad desarrollada entre los Estados miembros en el marco de la CPE, en la que ya participaban las instituciones. Práctica que ha continuado desarrollándose desde entonces $^{86}$. Pero esa participación se ha intensificado sobre todo en las situaciones

Portugal, Suecia, Irlanda, Grecia y Dinamarca). Otros ejemplos son Líbano y Filipinas, por mencionar los casos más recientes». El informe de la actual alta representante, F. Mogherini al Consejo sobre la puesta en marcha de la revisión del SEAE, incluye para el futuro: «Further developments in the role and responsibilities of EU Delegations [...]. This could include further reflections on the role of EU Delegations in facilitating and supporting coordination between Member States in providing consular assistance to EU citizens in third countries [...]", Progress Report of the High Representative to the Council. Implementing of the EEAS Review, Doc. 5113/16, del Consejo de 11 de enero de 2016.

Puede citarse algún precedente reciente de este tipo de protección referida a personas concretas, como el del italiano G. Regeni fallecido en El Cairo el 3 de febrero de 2016, cuyo cadáver hacía sospechar de tortura y respecto del cual la alta representante para AA. EE. y Política de Seguridad afirmó el 26 de julio de 2016 en respuesta a una pregunta parlamentaria: «The High Representative/Vice-President has personally raised the death of the young Italian doctoral researcher Giulio Regeni several times with the Egyptian Foreign Minister Sameh Shoukry and stressed the need to conduct a thorough, independent and transparent investigation, in close cooperation with the Italian authorities. The case has also been raised by the EEAS and Commission Officials in Cairo in their contacts with the Egyptian authorities. The EU supports all the initiatives the Italian authorities are taking in order to shed full light on the circumstances and to bring the perpetrators to justice», Pregunta parlmentaria núm. 2949/2016, de 12 de abril de 2016. En la misma línea, las respuestas de la alta representante a preguntas parlamentarias interesándose por la situación de ciudadanos británicos detenidos en Irán: «The case of Mr Kamal Foroughi is of utmost concern to the EU and has been raised on different occasions with the Iranian side, similarly to the cases of other European citizens of which the EEAS has been informed. While the primary responsibility for consular protection of EU citizens abroad lies with their Member State of origin, we will continue to closely monitor these cases and use every opportunity to raise them with the Iranian authorities [...]», ver las respuestas de 23 de marzo y 15 de junio, respectivamente las preguntas parlamentarias núm. 147/2016, y núm. 3668/2016. En el caso de un empresario italiano en prisión en Guinea Ecuatorial la Alta Representante señaló: «The HR/ VP is aware and following this case closely. The HR/VP is liaising with EU Member 
de crisis en las que los Estados miembros han recibido la ayuda de las delegaciones de la UE por distintas vías ${ }^{87}$. En ese sentido, las Directrices sobre protección consular de 2010 ya disponían que las delegaciones de la UE deben estar incluidas en los planes de emergencia y que, cuando lo soliciten uno o más Estados miembros y cuando proceda, tales delegaciones podrían prestar apoyo logístico a las misiones de los Estados miembros, especialmente durante las crisis ${ }^{88}$.

States represented in Equatorial Guinea. During a recent visit to Malabo, the EU Head of Delegation accredited to Equatorial Guinea raised with the authorities several human rights cases, including the case raised in the question. We have been informed that the Italian citizen in question has received consular assistance and was last visited on 7 February by the Spanish Consul in Bata. The authorities of Equatorial Guinea have been reminded of the EU's strong attention on this case. The improvement of human rights in Equatorial Guinea is a top priority for the EU in its relations with Equatorial Guinea», ver respuesta de 28 de marzo de 2014 a la pregunta parlamentaria núm. 1445/2014, de 11 de febrero del mismo año.

87 Como destacó la Comisión ante el PE el 1 de junio de 2011 en respuesta a la pregunta parlamentaria núm. 2795/2011, de 22 de marzo: «Lorsqu’une crise survient dans un pays tiers (qu'elle soit d'origine humaine ou naturelle) en entraînant la nécessité pour les États membres de venir en aide à des citoyens de l'Union européenne (ce que l'on appelle une "crise consulaire»), et à la demande de ces États membres, il convient d'apporter une assistance en recourant aux ressources existantes disponibles dans les délégations de l'UE». Respecto de los gastos de intervención urgentes «une ligne budgétaire ad hoc gérée par le Service des instruments de politique étrangère de la Commission, unité "opérations instrument de stabilité, réaction en cas de crise et consolidation de la paix», permet aux chefs de délégation de financer un soutien logistique d surgence. Cette ligne budgétaire a été mise en place dans le budget de l>UE (19 0606 «Coopération consulaire») en prévision de telles dépenses. Cette procédure a été utilisée dans le cas de l'évacuation de citoyens de l'UE de la bande de Gaza en 2009», lo que permitió evacuar a unas 100 personas en autobuses blindados.

Doc. 15613/10, ya citado, p. 3. Como destacó en representación de la Comisión F. Mogherini ante el PE el 20 de mayo de 2015 en respuesta a la pregunta parlamentaria núm. 9682/2014, de 25 de noviembre de 2014: «Since the establishment of the EEAS, a Consular Division was set up, which supports coordination and cooperation between the EEAS and Member States in order to contribute to the implementation of the aforementioned right of EU citizens to consular protection in third countries. The main areas of activity of the Consular Division to achieve this objective are: to support MS and EU Delegations in the event of a consular crisis; to give support to EU Delegations on consular cooperation in general. The main role of the EEAS/the EU Delegations is giving support to Member States in providing consular assistance to EU citizens, and does not consist of providing front line consular assistance themselves. However, in spite of the limited means at the disposal of the EEAS in this field, it has managed to bring 
El art. 12 se refiere a las reuniones de cooperación local, que deberán incluir un intercambio periódico de información sobre materias relativas a los ciudadanos no representados (como la seguridad de los mismos, las condiciones de reclusión, el acceso y notificación consular y la cooperación en caso de crisis) ${ }^{89}$. En estas reuniones, organizadas en estrecha cooperación con la delegación de la UE, los Estados miembros representados deben alcanzar, siempre que sea necesario, acuerdos prácticos para garantizar que los ciudadanos no representados reciban una protección eficaz. Presidirá las reuniones un representante de un Estado miembro, en estrecha cooperación con la delegación de la UE, a menos que los Estados miembros acuerden lo contrario.

\section{PROTECCIÓN EN CASOS DE CRISIS}

La necesidad de una adecuada preparación y cooperación en caso de crisis $^{90}$ ha sido planteada por la Comisión en numerosas ocasiones y constituye

added value in a number of crisis situations by contributing to the consular protection of EU citizens, the most recent examples of which are the crises in Yemen and Nepal. The EEAS also manages the CoOL (Consular Online) website, which connects Member States' consular departments and crisis centers as well as the EU Delegations for purposes of information sharing (mainly in crisis situations) and contingency planning... The EEAS also organizes and participates in consular exercises with EU Delegations and Member States in order to increase the overall capacity to respond to crisis situations, where consular assistance is needed. The EEAS also participates in the Council Working Group on Consular Affairs (COCON)».

Considerando núm. 19. Las Directrices sobre protección consular de 2010 establecían que en los países en que las circunstancias locales lo justifiquen, los jefes de misiones y las oficinas consulares organizarán, al menos, una reunión trimestral para debatir sobre la seguridad de los ciudadanos de la UE y tratar de manera automática cuestiones como las condiciones de las prisiones, los problemas relativos al acceso consular y compartirán información sobre posibles cambios en la legislación local con repercusiones en la función consular, sobre todo, si pueden afectar al trato a los detenidos, tratamientos médicos, procedimientos judiciales o asesoramiento jurídico disponible (especialmente abogados dispuestos a prestar servicios gratuitos a ciudadanos sin recursos). Las reuniones, presididas por un Estado miembro con apoyo de la delegación de la UE, servirán también para revisar la eficacia de los planes de emergencia de los Estados, y las mejores prácticas, Doc. 15613/10, de 5 de noviembre de 2010, pp. 4-5.

90 Sobre la asistencia de los ciudadanos de la UE en situaciones de crisis, Luis Norberto GONZÁLEZ ALONSO, «Protegiendo a los ciudadanos de la Unión más allá del Espacio de Libertad, Seguridad y Justicia: ‘̧hacia un nuevo modelo europeo de gestión consular de crisis?», en José MARTÍN Y PÉREZ DE NANCLARES, (coord.), La 
el objeto principal de las Directrices de 2010. Ello es lógico, teniendo en cuenta que en las grandes crisis ocurridas en diferentes puntos de planeta, bien como consecuencia de conflictos o bien derivadas de catástrofes naturales, se ven afectados numerosos ciudadanos de la UE. Así fue en Libia, Egipto y Bahréin después de los levantamientos de la primavera de 2011, o en Haití y Japón tras los terremotos de enero de 2010 y marzo de 2011, respectivamente, o más recientemente, con la epidemia de Ébola o las crisis humanitarias provocadas por el conflicto en Yemen y el terremoto en Nepal ${ }^{91}$. Esas situaciones han puesto en evidencia la importancia de que los ciudadanos de la UE puedan contar con la protección de cualquier Estado miembro independientemente de su nacionalidad y la necesidad de incrementar la cooperación entre los Estados miembros y con la UE, para optimizar la gestión eficaz de recursos.

Así, la Directiva busca establecer una clara división de responsabilidades entre Estados miembros representados y no representados y las delegaciones de la UE para garantizar una adecuada preparación y gestión de las crisis, lo que implica la necesidad de coordinar los planes de contingencia y de que en ellos se incluya plenamente a los ciudadanos no representados. Se busca, asimismo, reforzar la interoperabilidad entre el personal consular y otros expertos en gestión de situaciones de crisis. De ese modo, el art. 13,

dimensión exterior del Espacio de Libertad, Seguridad y Justicia de la Unión Europea, Madrid, 2012, pp. 383-407, especialmente pp. 394-400.

91 En Libia se encontraban cerca de 6000 ciudadanos de la UE al principio de la crisis y solo estaban representados ocho Estados miembros. En Egipto, donde estaban representados 22 Estados miembros, había al menos 100000 ciudadanos de la UE, la mayoría turistas en la región del Mar Rojo. En Bahréin con representación de cuatro Estados miembros había al menos 8800 ciudadanos de la UE. En Haití unos 2700 ciudadanos de la UE y en Japón, donde están representados todos los Estados miembros, salvo Chipre y Malta, había unos 37000 ciudadanos de la UE cuando se produjeron los terremotos. En estas crisis, la protección se coordinó mediante teleconferencias y la red Consular On Line, especialmente para compartir información con las autoridades consulares sobre la presencia de ciudadanos de la UE y las capacidades disponibles de los Estados miembros, COM (2011) 149 final, ya citado. En la epidemia de Ébola y tras la adopción el 18 de septiembre de 2014 de la Resolución 2177 (2014) del Consejo de Seguridad de la ONU sobre el brote del virus del Ébola (S/RES/2177/2014) el representante permanente de Francia ante la ONU recordó que, a iniciativa de Francia, la UE dispondría de un dispositivo de coordinación de las evacuaciones sanitarias de los ciudadanos europeos y del personal internacional desplegado sobre el terreno en el que Francia ponía a disposición sus propias capacidades de evacuación, «Pratique Française du Droit International», AFDI, 2014, pp. 637-640. 
se refiere a la elaboración de planes de emergencia locales, a la gestión de las situaciones de crisis, al papel del Estado de referencia o Estado que coordine la asistencia y a la posibilidad de solicitar el apoyo de instrumentos de la $\mathrm{UE}^{92}$.

Los planes de emergencia locales ${ }^{93}$ serán coordinados por los Estados miembros representados y con la delegación de la UE para garantizar que los ciudadanos no representados reciben asistencia plena en caso de crisis $^{94}$.

92 Desde 2015 los Estados miembros y el SEAE desarrollan el proyecto Consular Cooperation Iniciatives dirigido a explorar las posibilidades de desarrollar el papel de las delegaciones de la UE en su tarea de facilitar y apoyar la coordinación entre los Estados miembros en la protección a los ciudadanos de la UE en terceros países, tal como se acordó en las Conclusiones del Consejo sobre el SEAE de 17 de diciembre de 2013. Para ello, un equipo de Estados miembros interesados, bajo la supervisión general del COCON ha puesto en marcha por el momento cinco iniciativas en terceros Estados (Camboya, República Dominicana, Nepal, Nigeria y Túnez). El SEAE actúa como secretario del grupo para garantizar la armonización y la Comisión y la Secretaría del Consejo asisten a las discusiones. En cada uno de esos cinco países un Estado miembro asumió el papel principal y elaboró un proyecto de plan para el año 2015 sobre una plantilla común. Sobre esa base el grupo formuló una serie de conclusiones y recomendaciones y elaboró un primer informe que recoge las evaluaciones por país, las principales conclusiones y recomendaciones, y un marco conjunto de preparación de crisis, junto a las estadísticas globales sobre la protección a ciudadanos de la UE en el año 2015 elaboradas por el SEAE, a las que nos hemos referido al comienzo del trabajo. Ver Doc. 8347/16, adenda 1 y adenda 2 del Consejo de 29 de abril de 2016.

93 Según las Directrices de la UE sobre protección consular, es conveniente elaborar con antelación planes de emergencia y los planes elaborados por los Estados miembros representados en la capital deberían ponerse en común (para ayudar a los Estados que no han confeccionado el suyo y para conseguir un mayor grado de similitud entre ellos). Tales planes deberían revisarse periódicamente para asegurar que las actualizaciones de uno se reflejen en los demás. Los jefes de misión o su personal han de informarse mutuamente de la evolución sobre sus nacionales, localización, amenazas a su seguridad, instrucciones que han de comunicarles, especialmente en caso de reagrupación y evacuación, y de todos los recursos de que disponen, la creación de reservas de emergencia y los procedimientos para su utilización. Se destaca la importancia de la coordinación con terceros, por lo que los planes de emergencia deben ajustarse también a los del país de acogida, si procede, y a los de otros socios importantes (terceros países amigos, la ONU y las ONG), Doc. 15613/10, de 5 de noviembre de 2010, pp. 6-7.

94 El PE proponía varias enmiendas encaminadas a reforzar el papel de las delegaciones de la UE en la coordinación de los planes de emergencia, en el intercambio de información y en la gestión de las situaciones de crisis. Por ejemplo, establecía que en caso 
Las embajadas o consulados competentes serán informados de los preparativos para situaciones de crisis y, cuando proceda, participarán en ellos. La UE y los Estados miembros cooperarán estrechamente para garantizar una asistencia eficaz a los ciudadanos no representados y, cuando sea posible, se informarán mutuamente con la debida antelación de las capacidades de evacuación de que dispongan. Si lo solicitan, los Estados miembros podrán recibir ayuda de los equipos de intervención de la UE que incluyan expertos consulares, especialmente de los Estados miembros sin representación.

El Estado de referencia o los Estados miembros que coordinen la asistencia $^{95}$ serán responsables de coordinar toda la ayuda prestada a los ciudadanos no representados, con el apoyo de los demás Estados miembros afectados, la delegación de la UE y la central del SEAE. Los Estados miembros les proporcionarán toda la información pertinente sobre sus ciudadanos no representados presentes en el terreno ${ }^{96}$.

de crisis, las delegaciones de la UE serían las encargadas de coordinar la evacuación y prestar la asistencia necesaria para la misma; así como de coordinar y prestar la asistencia relativa a la preparación para y en situaciones de crisis, incluyendo una función específica para atender a los ciudadanos sin representación; y de coordinar y dirigir la asistencia y las operaciones de reunión de los ciudadanos sin representación y coordinar su evacuación.

95 El concepto de Estado de referencia alude a uno o más Estados miembros representados en un determinado tercer país y encargados de coordinar y dirigir la asistencia a ciudadanos no representados durante las crisis (considerando núm. 23). Aunque el COCON sigue trabajando sobre este concepto y otros similares, la propia Directiva habla del Estado de referencia o «los Estados miembros que coordinen la asistencia». Parece que, en la práctica, en situaciones de graves crisis, no se utiliza el concepto de Estado de referencia, sino que, a medida que se desarrolla la crisis y algunos países se preparan y actúan, por ejemplo, con el envío de aviones para la salida de sus nacionales, se mantiene comunicación constante entre las capitales para compartir información y la coordinación práctica sobre puntos de recogida de pasajeros, embarque, etc., se hace sobre el terreno, directamente entre las embajadas. Un ejemplo reciente es Sudán del Sur, donde Alemania e Italia enviaron aviones para permitir la salida de sus nacionales y ofrecieron plazas a los demás Estados miembros y otros países; y lo mismo hicieron Estados Unidos y Japón (información obtenida de manera oficiosa de la Dirección General de Españoles en el Exterior y de Asuntos Consulares y Migratorios).

96 Las Directrices sobre protección consular de 2010 destacan la importancia de que los planes de emergencia se basen en una información correcta sobre los ciudadanos de la UE que puedan verse afectados, registrada en formato de fácil comprensión, e invitan a las misiones de los Estados miembros a animar a sus nacionales a registrarse con carácter voluntario, especificando los datos mínimos que deberían recogerse a ese respecto y añadiendo en el anexo III un modelo de ficha de datos personales, Doc. 
Además, el Estado de referencia o los Estados miembros que coordinen la asistencia podrán solicitar, si procede, apoyo de instrumentos como la Dirección de Gestión de Crisis Consulares del SEAE y el Mecanismo de Protección Civil de la Unión ${ }^{97}$. En efecto, desde finales del año 2007, puede recurrirse al apoyo de este Mecanismo, actualmente regulado por la Decisión 1313/2012/UE, del PE y el Consejo de 17 de diciembre de 2013, que prevé esa posibilidad en su art. 16.7: «El Mecanismo de la Unión podrá también utilizarse para proporcionar apoyo de protección civil la asistencia consular para los ciudadanos de la Unión en catástrofes en terceros países en caso de que lo soliciten las autoridades consulares de los Estados miembros afectados».

La activación del Mecanismo, que permite poner en común y movilizar recursos (medios de transporte, asistencia sanitaria y evacuación, refugio temporal...) e intercambiar información ${ }^{98}$, se ha producido ya en situaciones de crisis graves en que se han visto afectados ciudadanos de la UE, como tras los atentados terroristas de Bombay en 2008, o en el contexto de la crisis de Libia $^{99}$.

15613/10, pp. 4 y 12. En España, la web del Ministerio de AA. EE. y Cooperación (http://www.exteriores.gob.es/) ofrece la posibilidad de inscripción en el registro de viajeros, para lo que se requiere una información mínima que coincide con la de la citada ficha.

97 DO L 347, de 20 de diciembre de 2013. El Mecanismo fue creado por Decisión 2001/792 del Consejo, de 23 de octubre de 2001 (DO L 297, de 15 de noviembre de 2001), refundida mediante Decisión 2007/779, del Consejo de 8 de noviembre de 2007 (DO L 314, de 1 de diciembre de 2007), incluyéndose desde entonces la posibilidad de utilización del mecanismo para apoyar la asistencia consular a los ciudadanos de la UE. Además de los 28 Estados miembros de la UE, participan en el Mecanismo Islandia, Noruega, Serbia, Turquía, la Antigua República Yugoslava de Macedonia y Montenegro.

98 La Comisión señaló en el PE en su respuesta de 1 de junio de 2011 a la pregunta núm. 2795/2011, de 22 de marzo: «L'activation de ce mécanisme peut offrir l'accès à un vaste réseau de ressources de protection civile disponibles au sein des 31 États qui y participent. Concrètement, et en fonction de la situation et des besoins précis, ce mécanisme peut notamment venir appuyer les opérations consulaires en facilitant la mise en commun de ressources de transport, organiser l'évacuation médicale de ressortissants européens grièvement blessés, mobiliser des abris d'urgence temporaires, de la nourriture, de l'eau et des infrastructures sanitaires, ainsi que déterminer les moyens de transport complémentaires disponibles».

99 En noviembre de 2008, un avión de evacuación sanitaria sueco cofinanciado por la Comisión evacuó a seis europeos heridos de Bombay. En Libia se activó el Mecanismo para ayudar a las autoridades consulares en la rápida evacuación de los ciudadanos de la UE, facilitando la puesta en común de transporte, buscando medios de transporte adicionales y cofinanciando los costes de transporte. Por ejemplo, Hungría puso a 


\section{PROCEDIMIENTOS FINANCIEROS}

Como ya hemos señalado, la Decisión 95/553/CE requiere, salvo caso de extrema urgencia, la autorización de las autoridades del Estado miembro de nacionalidad del solicitante para poder comprometer o conceder al ciudadano de la UE no representado cualquier anticipo, ayuda económica o gasto. Y, salvo renuncia expresa por parte de las autoridades del Estado de nacionalidad, exige al ciudadano un compromiso de reembolso de los gastos derivados de su asistencia, incluidas las posibles tasas notificadas. También hemos destacado que la Comisión ha manifestado en diversas ocasiones la necesidad de simplificar tales procedimientos, planteando incluso la creación de un sistema de compensación con financiación de la propia UE.

La opción de crear un sistema de compensación quedó descartada en la evaluación de impacto que acompaña a la propuesta de Directiva, en la que se señala que un mecanismo de reembolso o cámara de compensación de la UE facilitaría los reembolsos y garantizaría una mayor igualdad de trato entre los ciudadanos no representados, pero a cambio generaría importantes costes económicos y no permitiría aprovechar plenamente las sinergias con el Mecanismo de Protección civil ${ }^{100}$. De manera que la Directiva se decanta por la

disposición un avión, cofinanciado para evacuar de Trípoli a 29 ciudadanos rumanos, 27 húngaros, 20 búlgaros, 8 alemanes, 6 checos y otros 6 ciudadanos de la UE y de terceros países. Como destacó la alta representante ante el PE: «To support the EU's consular action, the EU Civil Protection Mechanism stepped into action on 23 February 2011 at the request of the Hungarian Presidency and the High Representative/ Vice President of the Commission to facilitate the pooling of transport and identifying additional transport means for evacuation. In this regard, the Commission's Monitoring and Information Centre (MIC) was cooperating closely with the EU Military Staff/Movement Planning Cell embedded in the MIC to facilitating access to Member States' military transport means. The MIC also co-financed up to $50 \%$ of individual transport operations' costs amounting to some EUR 112000 Overall, more than 5800 Europeans were evacuated». Véase respuesta de 17 de junio de 2011 a la pregunta parlamentaria núm. 2341/2011, formulada el 14 de marzo del mismo año.

100 Resumen de la evaluación de impacto que acompaña a la Propuesta de Directiva, ya citado, Doc. 18821/11, pp. 6-10. La Comisión estima que, dada la necesidad de recursos económicos y financieros adicionales, la implementación de un mecanismo o cámara de compensación de la UE generaría costes en la UE de al menos 112000 Euros anuales, a los que se añadirían los costes adicionales de creación y mantenimiento de ficheros electrónicos. La financiación de la UE supondría entre 16 y 31 millones de euros (según se financie el $50 \%$ o más) para un periodo de 6-7 años y los gastos adicionales de gestión del fondo a nivel de la UE representarían al menos 780000 euros. 
mera simplificación de los trámites, fijando un procedimiento general en art. 14, que se completa con los anexos I y II, prácticamente idénticos a los que acompañaban a la Decisión 95/553/CE y un procedimiento simplificado para situaciones de crisis en el art. 15.

Conforme al procedimiento general, los ciudadanos no representados deben comprometerse a reembolsar a su Estado los gastos de la protección y ese compromiso se recogerá mediante el formulario del Anexo I. Ahora bien, ha de hacerse en las mismas condiciones que los nacionales del Estado miembro que protege, por lo que solo se exigirá el reembolso de los gastos si el Estado que presta la protección impondría esa misma exigencia en iguales condiciones a sus propios nacionales ${ }^{101}$. Dicho Estado podrá, a su vez,

101 El considerando núm. 25 recuerda que los Estados miembros que asisten económicamente a sus nacionales lo hacen como último recurso y solo en situaciones excepcionales, cuando los ciudadanos no pueden obtener recursos económicos por otras vías, como transferencias de familiares, amigos o empleadores. En España, al margen del Real Decreto 8/2008, de 11 de enero por el que se regula la prestación por razón de necesidad a favor de los españoles residentes en el exterior y retornados (BOE, de 24 de enero de 2008), aprobado tras la entrada en vigor de la Ley 40/2006, de 14 de diciembre, del Estatuto de la Ciudadanía Española en el Exterior ( $B O E$, de 15 de diciembre de 2006), las ayudas de protección y asistencia consulares en el extranjero se regulan por la ORDEN/AEX/1059/2002, de 25 de abril de bases reguladoras de las ayudas de protección y asistencia consulares en el extranjero $(B O E$, de 14 de mayo de 2002), que permite conceder ayudas a los españoles en situación de necesidad para repatriaciones, evacuaciones, ayudas de subsistencia, ayudas extraordinarias o de emergencia, ayudas a detenidos, ayudas para asistencia jurídica y cualquier otra de carácter similar que se considere adecuada para atender a las necesidades que concurran en cada caso concreto, la mayor parte de carácter reintegrable, y regula el contenido y procedimiento de concesión de las mismas. El art. 7 de la Orden dispone que en los casos en que se preste la protección y asistencia previstas en el art. 20 TCE, se realizarán los gastos necesarios de conformidad con las normas acordadas al efecto entre los Estados miembros. Dicha Orden fue modificada por la Orden AEC/3119/2005, de 26 de septiembre, en lo relativo a las cuantías de las ayudas periódicas a detenidos españoles internados en centros penitenciarios en el extranjero ( $B O E$, de 10 de octubre de 2005). Puede verse sobre la asistencia económica a españoles detenidos en el extranjero, Xavier MARTÍ MARTÍ, "La política española de protección y asistencia consulares a los ciudadanos españoles detenidos en el extranjero", REDI, vol. 65, núm. 1, 2013, pp. 43-72, pp. 55-58. Respecto de las situaciones de crisis, el art. 40.3 de la Ley 2/2014 de la Acción y del Servicio Exterior del Estado en el Exterior ya citada dispone que cuando el Gobierno, en una situación de emergencia consular, decida intervenir en operaciones de asistencia en el extranjero, que comporten la utilización de recursos presupuestarios del Estado, podrá exigir el reembolso de la totalidad o parte de los mismos a quienes se hayan expuesto voluntariamente a riesgos sobre los 
solicitar el reembolso al Estado miembro de nacionalidad del ciudadano no representado, utilizando el formulario normalizado del anexo II y, en tal caso, el Estado de nacionalidad deberá reembolsar los gastos en un plazo razonable (no superior a 12 meses), pudiendo a su vez exigir el pago de los mismos al ciudadano.

Teniendo en cuenta que la asistencia en caso de detención o prisión puede incluir gastos indispensables y justificados inusualmente elevados para las autoridades diplomáticas o consulares del Estado miembro que la presta, como gastos de viaje, alojamiento o traducción, se establece la obligación de informar de estos posibles gastos al Estado miembro de nacionalidad del ciudadano no representado durante las consultas que han de tener lugar con carácter previo. El Estado miembro protector podrá solicitar al de nacionalidad el reembolso de estos gastos inusualmente elevados y aquel deberá reembolsarlos en un plazo razonable que no excederá los 12 meses. Ahora bien, de acuerdo con el principio de no discriminación, el Estado miembro de nacionalidad del ciudadano no representado no podrá exigirle que reembolse gastos que los nacionales del Estado miembro protector no se verían obligados a reembolsar ${ }^{102}$.

También era necesario simplificar los procedimientos financieros para situaciones de crisis, dada la peculiaridad de estas situaciones que obligan a dar una respuesta rápida a un número elevado de ciudadanos y así lo hace el art. 15. Por un lado, aunque el ciudadano no representado no hubiera firmado un compromiso de devolución, el Estado miembro protector podrá exigir el reembolso al Estado miembro de nacionalidad y éste podrá exigírselo a su vez al ciudadano de acuerdo con su normativa nacional. Por otra parte, cuando la situación afecte a un importante número de ciudadanos de la UE, el Estado miembro protector podrá solicitar al de nacionalidad que reembolse los gastos de manera proporcional, dividiendo el importe total de los gastos ocasionados entre el número de ciudadanos que recibieron protección. Además y puesto que dicho Estado podría haber recibido ayuda financiera del Mecanismo de Protección Civil, se prevé que las contribuciones del Estado miembro de

que el Ministerio de AA. EE. y de Cooperación informa en sus recomendaciones de viaje.

102 Considerando núm. 27. La enmienda núm. 52 del PE a la propuesta de Directiva centraba la responsabilidad de la protección en la propia UE, al establecer que, en tales situaciones la delegación de la UE coordinará con el Estado miembro de nacionalidad del ciudadano sin representación toda evacuación o ayuda necesaria que se le proporcione y que «el SEAE dispondrá de los recursos financieros necesarios para coordinar y prestar la asistencia relativa a la preparación para y en situación de crisis». 
nacionalidad del ciudadano se fijen, en tal caso, después de restar la contribución de la UE.

\section{CONCLUSIONES}

La protección del ciudadano de la UE no presentado en terceros países puede tener una importante relevancia práctica, como ponen de manifiesto los numerosos viajes que realizan los ciudadanos de la UE a terceros Estados y la escasa representación de los Estados miembros, sobre todo en algunas zonas del planeta. Las medidas puestas en marcha por la Comisión para facilitar el conocimiento del derecho por los ciudadanos parecen estar dando sus frutos, lo que previsiblemente llevará a un progresivo aumento de las solicitudes de protección.

Sin embargo, la limitada regulación de la protección que ofrece hasta la fecha la Decisión 95/553/CE, ha planteado muchas dudas, especialmente sobre su ámbito de aplicación y su alcance y contenido. Dudas a las que ha contribuido la falta de acuerdo al respecto entre las instituciones (Comisión y PE, principalmente) y los Estados miembros. La Directiva 2015/637 trata de despejar algunas de esas dudas. Por otra parte, la práctica en materia de gestión de situaciones de crisis y protección de los ciudadanos en tales situaciones ha reflejado la necesidad de estrechar la cooperación y mejorar la coordinación entre los Estados miembros y con la UE, particularmente desde la creación del SEAE. La Directiva se ocupa de ello, lo que debería redundar en una mejora de la efectividad de la protección del ciudadano en el futuro.

Entre otras cosas, la Directiva define los beneficiarios de la protección, ampliando el ámbito de aplicación personal para incluir a los familiares del ciudadano que sean nacionales de terceros Estados; y especifica cuándo debe entenderse que un ciudadano no está representado, permitiendo también aclarar dónde puede acudir el ciudadano no representado que se encuentra en dificultades en el extranjero. La regulación contenida en la Directiva contribuirá a mejorar la coordinación y cooperación entre los Estados miembros, y entre estos y la UE, especialmente en situaciones de crisis, al formalizar jurídicamente y dotar de carácter vinculante a muchas de las recomendaciones hasta ahora recogidas en las Directrices sobre protección consular revisadas por el Consejo en 2010, y al delimitar el papel de las delegaciones de la UE y la posibilidad de recurrir, a solicitud de los Estados que coordinen la situación, a los instrumentos de la UE, como el Mecanismo de Protección civil. También es positiva la simplificación de los procedimientos financieros para el reembolso de los gastos, pues esta era una cuestión que no estaba bien resuelta en la Decisión 95/553 y ocasionaba problemas en la práctica, lo que podía desmotivar la acción protectora de los Estados. 
Ahora bien, la nueva regulación no altera la naturaleza jurídica de la institución, cuyo alcance y contenido no han experimentado cambios sustantivos. Podemos seguir hablando de protección por afinidad, un tipo de protección muy similar en su contenido a la clásica asistencia consular reservada por el derecho internacional a los nacionales. A pesar de las propuestas del PE y como constata la propia Comisión, hoy por hoy, la práctica demuestra que el contenido de la protección sigue siendo equiparable al de la clásica asistencia consular, y así ha quedado recogido en la Directiva. No se trata de protección diplomática ni, en rigor, de protección consular a pesar de la terminología utilizada. Eso sí, se establece con mayor claridad la obligación para la embajada o consulado que presta la protección de proporcionarla en las mismas condiciones que a sus propios nacionales. Tampoco han tenido reflejo en la norma las iniciativas encaminadas a reconocer un mayor protagonismo de la UE en la protección de los ciudadanos que pudiera concretarse en una función de protección a desempeñar directamente por las delegaciones de la UE. La función de asistencia y protección de los ciudadanos en el extranjero continúa siendo, al menos por el momento, responsabilidad principal de los Estados miembros. 
